\title{
Einleitung zum 15. Band
}

Die Briefe des vorliegenden Bandes umfassen die Monate Oktober 1749 bis einschließlich Mai 1750. Zu Beginn des Zeitraums befand sich das Ehepaar Gottsched noch immer in Wien. Die Abreise wurde verschoben, nachdem sich nach der prestigeträchtigen Audienz vom 28. September 1749 (vgl. Band 14, S. XIXf.) eine weitere Möglichkeit eröffnet hatte, persönlich vor den kaiserlichen Herrschaften zu erscheinen. Man übergab den ersten Band der von Luise Adelgunde Victorie Gottsched übersetzten Geschichte der königlichen Akademie der schönen Wissenschaften zu Paris mit Gottscheds Widmung. Vor dieser zweiten Begegnung, die am 6. Oktober stattfand, waren die Gottscheds augenscheinlich damit befaßt, Freunden, Verwandten und Gönnern von den Ereignissen zu berichten. Einige wenige dieser Briefe sind überliefert. Sie werfen, gedruckt am Ende des vorigen und am Beginn des vorliegenden Bandes, ein Licht auf die Ereignisse und deren Wirkung auf das Leipziger Ehepaar, wobei je nach Adressat die Darstellung variiert.

Ein weiterer Brief aus diesen Tagen, von dem Frau Gottsched selbst eine Abschrift genommen und gleichzeitig (für welchen Zweck eigentlich?) die Begleitumstände seiner Entstehung festgehalten hat, gewährt einen punktuellen, aber möglicherweise signifikanten Einblick in Gesprächsthemen, die in der Wiener Adelsgesellschaft in Gegenwart des Literatenpaares Gottsched geführt wurden: Der preußische König Friedrich II. hatte als Liebhaber der französischen Literatur in einem Brief an Prosper Jolyot de Crébillon dessen 1748 entstandene Tragödie Catilina gerühmt. Gegenüber Crébillons Widersacher Voltaire äußerte er sich wenig später abfällig über das Werk. Beide Briefe gelangten in die Öffentlichkeit. Auch in Wiener Salons nahm man davon Kenntnis. Die Diskrepanz der Aussagen liegt auf der Hand. Frau Gottsched wurde von den adligen Gastgeberinnen gleichwohl aufgefordert, die Unterschiede schriftlich zu benennen. Sie ließ es nicht bei einer Beschreibung bewenden, war auch nicht willens, der Anpassung an die Erwartungshaltung der jeweiligen Adressaten als läßliches Vergehen mit Verständnis zu begegnen. Vielmehr empörte es sie, daß Friedrich, der als Autor des Antimachiavel Täuschung und List verurteilt hatte, um der Bewunderung 
französischer Schöngeister willen unaufrichtig war. Für sie war das um so verwerflicher, als sich die Taten der Könige vor den Augen des Universums vollziehen, ihre Vorbildwirkung also von den Akteuren in Rechnung gestellt werden sollte. Vermutlich entsprach dieses Urteil über Friedrich den Erwartungen der Wiener Gastgeber. Es ist indes auch Ausdruck der moralischen Sensibilität der Gottschedin und offenbart grundsätzliche Vorbehalte gegenüber dem preußischen König, die auch in ihrem noch zu erwähnenden Widmungsgedicht für die Kaiserin zum Vorschein kommen.

Am 6. Oktober erfolgte die Übergabe der Akademiegeschichte. Im unmittelbaren Anschluß traten die Gottscheds die Heimfahrt an. Im Gegensatz zur Hinreise waren Besuche und Aufenthalte nicht vorgesehen. Das Ehepaar Gottsched traf am 13. Oktober in Leipzig ein (Nr. 11, Erl. 13), die Reisezeit von knapp sieben Tagen wurde mit Erstaunen zur Kenntnis genommen (Nr. 24). Der geplante Rückkehrtermin Michaelis, 29. September (Band 14, S. 560), konnte nicht eingehalten werden, die Verspätung von zwei Wochen dürfte aber hinnehmbar gewesen sein. Gottsched stand sofort wieder für besondere universitäre Aufgaben zur Verfügung. Drei Tage nach der Ankunft war er einer der drei Repräsentanten der Universität, die vor dem Kurprinzen und erstmals auch der Kurprinzessin sowie einer ansehnlichen Hofgesellschaft referierten, wie es sich mittlerweile während der fürstlichen Messebesuche eingebürgert hatte. Üblicherweise standen wissenschaftliche Themen auf der Tagesordnung. Daß Gottsched seine jüngst verfaßte und mit Huldigungen auf die Kaiserin versehene Ode Das Carlsbad vortrug, war eine Ausnahme, ist aber gleichwohl symptomatisch für Gottscheds geistige Ausrichtung in dieser Zeit. Die Wochen und Monate nach dem Wiedereintreffen standen insgesamt im Zeichen des Wienaufenthalts. Das gilt für die Korrespondenz ebenso wie für Gottscheds poetische und akademische Arbeiten.

Auffällig ist zunächst eine Häufung von Briefen aus Wien. Etliche Personen, mit denen das Ehepaar Gottsched in Wien bekannt geworden war, sandten Grüße oder erörterten gemeinsame Vorhaben. Auch in anderen Korrespondenzen war der Wienbesuch ein bevorzugtes Thema. Nicht allein die Briefpartner, die von Gottsched unmittelbar ins Bild gesetzt worden waren, sahen sich zu Rückmeldungen veranlaßt, wie sie in Briefen aus Kassel, Königsberg oder Gera zu finden sind. Da die Wienereignisse über Zeitungen publik gemacht worden waren, stimmten sich auch weitere Korrespondenten auf das Thema ein, bei denen der Eindruck entstanden war, daß diese „Reise das Augenmerck der Welt“ auf sich gezogen hat (Nr. 180). Man 
feierte Gottscheds Triumphe. Alsbald kamen auch die Gerüchte und Vermutungen zur Sprache, die sich um Gottscheds Wienreise rankten. Caroline von Seckendorff war von mehreren Personen versichert worden, daß Gottsched Sachsen wohl verlorengehen werde (Nr. 19). Aus Berlin berichtete der reisende Schweizer Theologe Johann Georg Schultheß mit einer gewissen Häme bereits Ende September nach einem Besuch Leipzigs an seinen Mentor Johann Jacob Bodmer in Zürich: „Gottsched habe nicht können sprechen; er ist in Carlsbade gewesen und soll von dannen nach Wien gereiset seyn. Vielleicht wendet er sich zu den Katholiken, ihren Geschmack zu reinigen, weil es ihm bey seinen Mitbürgern nicht gelingen wollen." Nach Gesprächen in Berlin wurde es wenig später fast zur Gewißheit: „Gottsched soll Leipzig ganz verlassen $\mathrm{u}$. in Wien seine Wohnung aufgeschlagen haben, allwo er bei der Ritter=Akademie, die daselbst angeleget werden soll, eine ansehnliche Stelle verhoffet. "Ähnliche Annahmen, die durch die Behauptung eines Übertritts zum Katholizismus verstärkt wurden, kursierten an vielen Orten, wie Briefe aus Königsberg und Nürnberg zeigen. Gottscheds alter Vertrauter Christian Clodius hatte es in Zwickau vernommen und war sichtlich erleichtert, als die verstörende Meldung von Gottsched dementiert wurde. Georg Matthias Bose zufolge „, [ging] in dem gantzen orthodoxen Wittenberg die Rede ..., Ew: HochEdelGebohrnen, wären zur römischen Kirchen übergetreten“ (Nr. 13). Auch weitere Gerüchte waren im Schwange: Luise Adelgunde Victorie Gottsched habe die Kaiserin in Versen angeredet und sei zur kaiserlichen Poetin gekrönt worden, Gottsched soll baronisiert und mit einer goldenen Kette beschenkt worden sein. Im Vergleich zum Verdacht des Glaubenswechsels waren das Curiosa.

Allerdings waren die Gerüchte nicht gänzlich unbegründet, zumindest was die Pläne einer Etablierung in Wien anbetrifft. Gottsched hatte schon mehrfach mit dem Weggang aus Leipzig geliebäugelt. Nach dem glanzvollen Empfang in Wien und dem Ausspruch der Kaiserin, er sei der „Meister der deutschen Sprache" (Band 14, S. 610), konnte er leicht auf den Gedanken geraten, in Wien zur rechten Zeit der rechte Mann am rechten Ort zu sein. Ganz offenbar hatte er in Wien Absprachen getroffen und Unterstützer gefunden, die auf seine Person gemünzte Projekte befördern und an Entscheidungsträger lancieren konnten. Schon Anfang 1749 hatte Gott-

${ }^{1}$ Schultheß an Bodmer, Berlin 27. September 1749 und Berlin ohne Datum. In: Jakob Bächtold (Hrsg.): Briefe von Joh. Georg Schultheß an Bodmer. In: Zürcher Taschenbuch N. F. 17 (1894), S. 1-46, 5-13, 11 und 26-29, 28. 
sched die Gründung einer Deutschen Gesellschaft in Wien angeregt, wofür es indes an allen Voraussetzungen fehlte (Band 14, S. 155). Während des Besuchs aber war ein Projekt viel größeren Ausmaßes erwogen worden, die Gründung einer Akademie der Wissenschaften. Genauere Informationen fehlen, aber in seinem Brief vom 5. November 1749 teilte Joseph Heinrich Engelschall mit, daß Joseph von Petrasch dem zuständigen Minister Friedrich Wilhelm von Haugwitz Gottscheds „Entwurf zu Errichtung einer Akademie der Wissenschaften ... zu Berathschlagung mit beyden Kajserl. Maj." überreicht habe (Nr. 24). Wie und wann Petrasch den Entwurf erhalten hat, ist nicht bekannt, und auch für den weiteren Verlauf gibt es nur indirekte Belege. Petrasch hat Gottsched offenbar eine leitende Position in der Akademie in Aussicht gestellt, dies aber an die Bedingung des Übertritts zur katholischen Kirche geknüpft, was Gottsched sofort abgelehnt hat. Dies jedenfalls läßt sich Worten Johann Christoph Löschenkohls entnehmen, der nun im Namen Nicolaus Graf Esterhasys seinerseits anbot, in dieser Sache tätig zu werden: „Wir sehen nunmehro den uns zu schickenden Entwurff mit dem grösten Verlangen entgegen " (Nr. 28). Gottsched sandte auch ihm ein Exemplar, ${ }^{2}$ das entgegen der ursprünglichen Absicht nicht an die Kaiserin, sondern erneut an Haugwitz gelangte. Löschenkohl hatte wenig später eine Unterredung mit dem Minister, in der er sich für das Projekt verwenden wollte. Die Angelegenheit blieb eine Weile in der Schwebe. Nach einem weiteren Gespräch mit Haugwitz teilte Löschenkohl am 7. Januar 1750 mit, „daß es mit Zustandebringung des gemachten Entwurfs zu einer Academie nicht angienge“ (Nr. 86). Gründe wurden nicht angegeben. Rückblickend gewinnt man nicht den Eindruck, daß der Realisierung des Akademieplans in Wien größeres Interesse entgegengebracht wurde. Allerdings ist die Unternehmung auch nicht gänzlich in Vergessenheit geraten. In der Vorgeschichte der Wiener Akademie der Wissenschaften wird Gottscheds Plan nach den sicher ungleich intensiveren Aktionen von Gottfried Wilhelm Leibniz immerhin erwähnt. ${ }^{3}$

\footnotetext{
2 Damit waren zwei Exemplare nach Wien gelangt, ein weiteres Exemplar verblieb in der Gottschedschen Bibliothek bis zu deren Versteigerung (Nr. 28, Erl. 2). Bislang konnte der Text nicht aufgefunden werden.

${ }^{3}$ Vgl. Joseph Feil: Versuche zur Gründung einer Akademie der Wissenschaften unter Maria Theresia. In: Jahrbuch für Vaterländische Geschichte 1 (1861), S. 319-407, 322-324; Richard Meister: Geschichte der Akademie der Wissenschaften in Wien 1874-1947. Wien 1947, S. 14.
} 
Den Bescheid über die Ablehnung verband Löschenkohl mit der Aufforderung, einen „andern Vorschlag“ zu unterbreiten, „wie und auf was vor Art sie hier seÿn könten“. Gottsched ging sofort darauf ein und erneuerte den Wunsch, den er bereits an seinen eifrigsten Unterstützer Franz Christoph von Scheyb herangetragen hatte: Er sah sich als Erzieher oder Sprachlehrer des Erzherzogs bzw. der kaiserlichen Kinder. Nach der Erfahrung mit Petrasch hatte Gottsched gegenüber Scheyb vorab seine Ablehnung einer Konversion erklärt. Seine Begründung, wie dennoch ein gedeihliches Wirken möglich sein würde, ist an Scheybs Gegenargumentation gut zu erkennen (Nr. 69). Anders als Petrasch wollte Scheyb Gottsched keineswegs zu einem demonstrativen Bekenntnis nötigen, aber die heimliche Zusage einer späteren unauffälligen Konversion schien ihm unumgänglich. Zwar schloß er nicht gänzlich aus, daß Gottsched unter bestimmten Einschränkungen auch als Protestant dieses Amt wahrnehmen könne, aber große Chancen räumte er dieser Konstellation nicht ein.

Löschenkohl gab sich gar nicht erst die Mühe, auf Gottscheds Gründe einzugehen. Unumwunden erklärte er, daß Gottscheds „absehen das allerschwereste ja gantz und gar unmöglich wäre, indeme solches, daß ein Protestant die Käÿs: Herrschafften unterrichten sollte, von denen hiesigen Principiis wie Tag und Nacht unterschieden ist" (Nr. 100).

Mit dieser Auskunft waren Gottscheds Pläne für Wien am Ende. Gottsched ließ sich davon indes nicht beirren. Es ist ohnehin nicht zu ermessen, wie ernst es ihm damit wirklich war. Die Kompromißlosigkeit in puncto Glaubenswechsel könnte eine selbsterrichtete Barriere gewesen sein, die die Realisierung erschweren oder verhindern sollte, denn daß das während des Besuchs genossene Klima der Zustimmung und des Entgegenkommens einzigartig und nicht dauerhaft sein würde, dürfte Gottsched klar gewesen sein. Das gewonnene Ansehen in Wien und andernorts war auch ohne konkretes Ergebnis ein kostbares Gut und möglicherweise ein größerer Trumpf, als es das mit Konkurrenzdruck und den Unwägbarkeiten des höfischen Klientelsystems verwobene Wirken in Wien gewesen wäre. Er brachte sich folglich auch ohne konkrete Absichten in Erinnerung. Dies war seine Strategie, bevor er in Wien eintraf. Er behielt sie nach der Reise bei, wie ein Blick auf Gottscheds poetische Produktion der Folgewochen lehrt.

In der Ode Die Argonauten, die Gottsched anläßlich der Aufnahme neuer Ritter in den exklusiven Orden vom Goldenen Vlies durch deren Großmeister Kaiser Franz I. Stephan verfaßte, sind Themen der antiken 
Sage, der gefahrvolle Erwerb des Goldenen Vlieses durch die Argonauten unter ihrem Führer Jason, mit einer Huldigung an Franz Stephan, den „Jason unsrer neuen Zeit", ${ }^{4}$ verknüpft. Selbst die Namen der neuen Ordensritter - Gottsched ist sehr wahrscheinlich in Wien jedem von ihnen begegnet - brachte Gottsched in den Versen unter.

Mit dem Gedicht Die Kayserinn am Theresien=Fest 1749. Allerunterthänigst besungen ließ Gottsched seinen Wienaufenthalt noch einmal Revue passieren und bemühte alle Register seiner Ausdruckskunst, um die unvergleichliche Erscheinung der Kaiserin und ihre alles überragende Wirkung zu schildern, wobei neben der gesamten kaiserlichen Familie auch die Fürstin Maria Carolina von Trautson als Erzieherin der Kinder (und maßgebliche Vermittlerin der Audienz) mit eigenen Passagen bedacht wurde. Die Verse fanden Anklang, die Fürstin war bei der Lektüre zu Tränen gerührt. Das Manuskript der Ode wurde abgeschrieben und verbreitet, gelangte vor die Augen der Kaiserin und fand dort den „vollkommensten Beÿfall“. So jedenfalls Johann Christoph Löschenkohl, der ergänzte: „die gantze Wiennerische Welt ist davon völlig bezaubert", zugleich aber anwies, das Werk „absolute auswertig“ drucken zu lassen, da es sonst seinen Wert verlöre (Nr. 53). Gottsched ließ sich davon überzeugen, der Druck erschien in Regensburg und begeisterte auch Gottscheds Korrespondenten. Doch nicht überall wirkte der Zauber. Vor den Augen und Maßstäben seiner literarischen Antipoden konnte Gottsched mit den Versen nicht bestehen. Johann Wilhelm Ludwig Gleim hatte nach der Lektüre „einen Satirischen Kützel“ und wollte seinem Korrespondenten Karl Wilhelm Ramler „einen Beweiß schicken, daß Gottsched nicht in Wien gewesen, und daß Gedicht auf die Kayserin nicht gemacht hätte. Denn wie könte der große Gottsched ein so schlechtes Gedicht machen und wie könte die große Kayserin den Verfasser eines so schlechten Gedichts vor sich kommen und so bedenckliche Dinge sagen laßen, als die schönste Frau begehrt?"5 Auch in Wien erntete Gottsched nicht ungeteilte Zustimmung. Franz Heinrich Graf Schlick vermißte in den Versen die Würdigung der Staatskunst der Kaiserin und benannte dieses Defizit seinerseits in Versen, die an Gottsched gelangten. Gottsched replizierte mit einem weiteren Gedicht, gab dem Grafen uneingeschränkt recht, rühmte dessen kritische Fähigkeiten, rechtfertigte seine Einseitigkeit

${ }^{4}$ Gottsched, Zwey Gedichte, S. 8.

5 Gleim an Ramler, Halberstadt 6. Februar 1750. In: Carl Schüddekopf (Hrsg.): Briefwechsel zwischen Gleim und Ramler. Band 1. Tübingen 1906, S. 209-212, 210. 
mit der Macht der persönlichen Erscheinung der Kaiserin, die ihn überwältigt habe, und machte geltend, daß die Fülle ihrer Qualitäten bestenfalls von Heerscharen von Dichtern, die jeweils einzelne Vorzüge feiern, dargestellt werden könne. „Wir könnten zehnmal zehn Theresiaden schreiben; Doch würde noch weit mehr zu rühmen übrig bleiben. "6 Auch dieses Gefecht im Medium höfischer Komplimentierkunst wurde an die richtigen Adressen vermittelt und legte Gottsched, wie Friedrich Wilhelm Weiskern vermeldete, am kaiserlichen Hofe ungemeine Ehre ein (Nr. 151).

Mit Löschenkohls Brief vom 25. Oktober 1749 erfuhren die Gottscheds erstmals von den Geschenken, die die Kaiserin dem Ehepaar als Gegengabe für die ihr gewidmete deutsche Ausgabe der Geschichte der königlichen Akademie der schönen Wissenschaften zu Paris, zugedacht hatte. Luise Adelgunde Victorie Gottsched war die Übersetzerin des Textes, Gottsched der Verfasser des Widmungsgedichts. Sie wurde mit „einer recht schönen HaarNadel von Brillanten“, er mit "einer goldenen Tabattiere die auch mit etlichen Brillanten besetzet ist" beehrt (Nr. 16). Die Geschenke wurden von der Fürstin Trautson an Nicolaus Graf Esterhasy übergeben, der die Weiterleitung organisieren sollte, zunächst aber dafür sorgte, daß die Stücke in Wien herumgezeigt wurden und, wenn man den Briefmitteilungen Glauben schenken kann, Verwunderung und Beifall erregten. Löschenkohl verband mit der Nachricht sogleich die Anweisung, Danksagungen in Versgestalt für die Kaiserin und die Fürstin herzustellen. Man hätte das Gottsched nicht sagen müssen: Größtmögliche Publizität war ohnehin in seinem Sinne, und die Resonanz in den Briefen seiner Korrespondenten veranschaulicht den beträchtlichen Prestigegewinn, den die Geschenke weit über ihren materiellen Wert hinaus bewirkten. Aber die Anweisung des hoferprobten Löschenkohl macht einmal mehr deutlich, daß sie auch vonseiten des Hofes nicht als diskrete Dankesgaben, sondern als Teil einer Inszenierung auf den Weg gegeben wurden. Gottsched begab sich ans Werk, seine Ode, die Verse für die Fürstin Trautson und auch das Dankschreiben der Gottschedin wurden alsbald nach Wien gesandt. Nur die besungenen kaiserlichen Geschenke kamen nicht von der Stelle. Sie konnten angeblich nicht mit der Post transportiert werden. Als Bote wurde der Hofmeister des Wiener Gesandten in Kursachsen verpflichtet, der im Begriff war, nach Dresden aufzubrechen. Seine Abreise verzögerte sich, und auch sein Reise-

${ }^{6}$ Gottsched, Gedichte, 1751, 2, S. 523. 
tempo entsprach nicht den Erwartungen. In Wien wurde man ungeduldig, als nach drei Wochen immer noch kein Signal über die Ankunft der Geschenke eintraf. Die Dankschreiben an die Kaiserin sollten nicht übergeben werden, bevor man sicher sein konnte, daß die Präsente ihre Bestimmung erreicht haben (Nr. 53). Nach dem Eintreffen in Dresden konnte Joseph Anton von Wackerbarth die Kostbarkeiten am 16. Dezember wohlverwahrt und mit seinem Siegel versehen nach Leipzig schicken, und mit Datum vom 20. Dezember konnte Gottsched endlich ihren Eingang bestätigen. In Wien wurden die Dankgedichte überreicht. Sie fanden, so Löschenkohl, „den allervollkommensten Bë̈fall“ (Nr. 100). Vereint wurden sie im Frühjahr 1750 in den Gesammleten Neuesten Gedichten Gottscheds in Königsberg veröffentlicht. Neben bereits Bekanntem war ein weiteres die Kaiserin verklärendes Gelegenheitscarmen Gottscheds enthalten, als Anlaß diente die Geburt der Tochter Johanna Gabriela. Schließlich brachte sich Gottsched dadurch in Erinnerung, daß er die neue, die vierte Auflage der Redekunst dem Erzherzog Joseph zum 9. Geburtstag widmete. Der Widmungstext erinnerte an den huldvollen Empfang durch das kaiserliche Paar und die halbstündige Unterredung mit dem Knaben, Gottsched ging auf dessen Münzliebhaberei und -sammlung ein. Die Widmung erzeugt bei aller Respektbekundung den Eindruck einer gewissen Vertrautheit mit der kaiserlichen Familie, und das sicher nicht absichtslos. Exemplare der Redekunst und des zweiten Bandes der Geschichte der königlichen Akademie der schönen Wissenschaften zu Paris mit dem Dankgedicht der Gottschedin trafen Mitte März in Wien ein und gelangten auf dem schnellsten Wege an die vorgesehenen Adressen.

$\mathrm{Zu}$ den bemerkenswertesten Phänomenen der Reisenachbereitung gehört sicherlich die Tatsache, daß Gottsched die Reise nach Wien und den Aufenthalt in der Kaiserstadt im Medium des lateinsprachigen akademischen Schrifttums beschreibt. Selbst die Kaiserin war überrascht. ${ }^{7}$ Ungewöhnlich ist sowohl die Aufbereitung eigener Reisen in diesem Rahmen ${ }^{8}$

\footnotetext{
7 Im Bericht über das Wiener Interesse an den Singularia Vindobonensia heißt es: „Daß ihro Majestät gefragt haben: Lateinisch? kömt daher weil sie so viele deutsche Sachen bekommen, und unversehens etwas lateinisches erhalten." Scheyb an das Ehepaar Gottsched, Wien 6. Juni 1750, Leipzig, UB, 0342 XV, Bl. 271-273, 272r.

${ }^{8}$ Vgl. Maria Lesigang-Bruckmüller: Eine oratio academica als Reisebericht? Johann Christoph Gottscheds Reise nach Wien im Spiegel seiner Universitätsrede Singularia Vindobonensia. Wien, Institut für Klassische Philologie, Dissertation, 2017, S. 15 (http://othes.univie.ac.at/51135/1/48897.pdf).
} 
als auch die Tatsache, daß Gottsched, der Protagonist popularisierender Deutschsprachigkeit, eine autobiographisch-erzählende Darstellung im Latein der Gelehrtenkultur vorlegte. Genau besehen gibt es indes Gründe für diese Entscheidung. Zur Erklärung wird man zunächst zu bedenken haben, daß Gottsched gewählter Prokanzler für die Magisterernennung dieses Zeitraums war. ${ }^{9}$ In dieser Eigenschaft hatte er eine Einladung zur Magisterprüfung zu veröffentlichen. Üblicherweise war dies mit der Erörterung eines Sachthemas verbunden. Am Ende der Prozedur, zur feierlichen Magisterpromotion, mußte eine Rede gehalten werden. Für beide Textsorten war Latein eine Selbstverständlichkeit. Für die Erarbeitung neuer Themen könnte schlicht die Zeit gefehlt haben, während die Reiseeindrücke und die mentale Ausrichtung auf Wien präsent und vergleichsweise einfach abrufbar waren. Es ist auch daran zu erinnern, daß Gottsched seine Reise als Studien- und Bibliotheksreise deklariert hatte, die der Auffindung unbekannter Zeugnisse älterer deutscher Literatur dienen sollte. Latein wäre dann das geeignete Medium gewesen, um dem Charakter einer Gelehrtenreise auch in der Sprachwahl Ausdruck zu verleihen. Auch die Werbung in eigener Sache ist als Motiv nicht auszuschließen. Gottsched konnte einigermaßen sicher sein, daß seine Deutschkompetenz in Wien anerkannt war und keines Beweises bedurfte. Er wußte aber auch, daß konservative Kräfte im Gebrauch des Deutschen einen Angriff auf das akademische Latein sahen, und schon 20 Jahre zuvor war ihm angeraten worden, für Karrierezwecke einen Befähigungsnachweis in Latein vorzulegen (Band 1, S. $164 \mathrm{f}$. und 179; Band 3, S. 271; Band 10, S. 75). Um möglichen Verdächtigungen seiner Lateinfähigkeit oder dem Vorwurf, daß der Gebrauch des Deutschen eine Kompensation mangelnder Lateinkenntnis sei, zuvorzukommen, eignete sich ein Text recht gut, dem seines Inhaltes wegen die Aufmerksamkeit in Wien sicher war.

Neben den unterschiedlichen Vindobonensia verdienen weitere Aktivitäten Gottscheds im Bandzeitraum wenigstens eine kurze Erwähnung. Die Beanspruchung als Prokanzler beschränkte sich nicht auf die Textproduktion. Er war in das gesamte Verfahren der Magisterbewerbung, -prüfung und -promotion ${ }^{10}$ eingebunden. Der Zeitaufwand war beträchtlich, so daß Gottsched den Verzug einer Briefantwort mit dem Verweis auf sein „da-

9 Zur Genese und Funktion des Amtes vgl. Georg Erler: Leipziger Magisterschmäuse im 16., 17. und 18. Jahrhundert. Leipzig 1905, S. 11-24.

${ }^{10}$ Vgl. Leipziger Merkwürdigkeiten Auf das 1748 Jahr, S. 26-30, 50-55. 
mahliges Procancellariat, welches mir beÿ der Magister Promotion viel zu thun machte", glaubhaft entschuldigen konnte (Nr. 200).

Infolge der Reise war in der zweiten Hälfte des Jahres 1749 Gottscheds Neuer Büchersaal nicht erschienen. Auf dieses Instrument öffentlicher Wirksamkeit zu verzichten, war um so weniger in Gottscheds Sinn, als ihn nicht selten Rückmeldungen über den Erfolg beim Publikum erreichten. Wahrscheinlich hat er sich bald nach der Rückkehr nach Leipzig der Weiterführung der Zeitschrift gewidmet. Seit Januar 1750 konnte der Neue Büchersaal wieder in gewohnter Regelmäßigkeit erscheinen.

Die Gedenkschrift auf den im Januar 1749 verstorbenen Reichsgrafen Ernst Christoph von Manteuffel sollte ursprünglich bereits zur Ostermesse 1749 vorliegen. Nicht nur Jean Henri Samuel Formey dürfte Zweifel daran geäußert haben, daß die Ausgabe überhaupt noch zustandekommt (Nr. 93). Vermutlich waren die Texte auf Gottscheds Schreibtisch liegengeblieben, und Gottsched war jetzt an einem raschen Erscheinen interessiert. Das könnte auch ein Grund dafür gewesen sein, daß Gottsched nicht seinen häufig ausgelasteten Hausverleger Bernhard Christoph Breitkopf, sondern Johann Gabriel Büschel, dem auch Scheybs Lobrede anvertraut wurde, für den Druck in Anspruch nahm. Anfang März konnte Gottsched die gedruckten Exemplare des Ehrenmaals verschicken. Die Geschichte der königlichen Akademie der schönen Wissenschaften zu Paris hingegen wurde in der Breitkopfschen Druckerei hergestellt, wenn sie auch mit der Verlagsangabe Johann Paul Krauß in Wien erschien. Die Anzeige des zweiten Bandes der von Frau Gottsched stammenden Übersetzung im Februarstück des Neuen Büchersaals enthält den Vermerk: „Der dritte Theil ist auch schon im Drucke". ${ }^{11}$ Diese Mitteilung darf auch als Hinweis auf die Anstrengung verstanden werden, der sich die Übersetzerin seit der Rückkunft nach Leipzig unterzogen hat.

Johann Christoph Löschenkohl forderte Gottsched Anfang Oktober 1749 auf, „mit ersterer Post“ einen Katalog sämtlicher Veröffentlichungen beider Gottscheds mit Preisangaben zu überschicken (Nr. 7). Als Grund für die Eile wird nur angegeben, daß Graf Esterhasy und Fürstin Trautson danach verlangen. Reichlich zwei Wochen später erfolgte bereits eine Mahnung. Daß das Verzeichnis nicht mit der nächsten Post abgeschickt wurde, lag nicht an Gottscheds Nachlässigkeit. Im Gegenteil. Gottsched wollte das

${ }^{11}$ Neuer Büchersaal 9/2 (1750), S. 185. 
Schriftenverzeichnis offenbar in ansehnlicher Gestalt präsentieren und ließ einen Druck anfertigen. Neben Löschenkohl erhielten auch andere Briefpartner diese Bibliographie (Nr. 180, Nr. 126), von der freilich bislang kein Exemplar ermittelt werden konnte.

Schon im Mai 1749 hatte sich Gottsched bei Hartmann von Geusau nach der Bereitschaft erkundigt, eine Molièreübersetzung in Angriff zu nehmen (Band 14, S. 376). Was dort nicht erkennbar ist: Wahrscheinlich handelte Gottsched im Auftrag des Hamburger Verlegers Johann Christian Herold. Aus einem Brief des Hamburger Redakteurs Joachim Friedrich Liscow vom 12. Februar 1749 ist zu erfahren, daß Herold schon lange nach geeigneten Übersetzern für eine deutsche Ausgabe der Werke Molières suchte. ${ }^{12}$ Auch Daniel Wilhelm Triller, dessen dichterisches Werk Herold verlegte, kam in Betracht. Er beriet sich daraufhin offenbar mit Gottsched, dessen Konzept für die Ausgabe von Triller an Herold vermittelt wurde (Nr. 36). Gottsched wollte den in Übersetzungen aus dem Französischen erfahrenen Johann Daniel Heyde gewinnen, der sich zumindest zu einer Prosaübersetzung bereitfand. 1752 erschienen Des Herrn Moliere sämmtliche Lustspiele. Der nur mit der Initiale B gekennzeichnete Übersetzer hieß Friedrich Immanuel Bierling. Auch er verzichtete auf eine Versübertragung und rechtfertigte dies im Vorbericht. Auf welchem Wege der in Leipzig lebende Bierling mit dem Projekt betraut wurde und ob Gottsched die Hand im Spiel hatte, konnte nicht festgestellt werden.

Seit ihrer Gründung nahm Gottsched lebhaften Anteil am Geschick der Königsberger Deutschen Gesellschaft. Als Berater schlug er Arbeitsthemen vor, beteiligte sich an der Herausgabe der Schriften und sorgte für die Gewinnung neuer Mitglieder der Gesellschaft. Die wachsende Mitgliederzahl zog ein höheres Korrespondenzaufkommen nach sich, sofern die Königsberger auf Kommunikation mit ihren auswärtigen Mitgliedern nicht gänzlich verzichten wollten. Es hatte gewiß auch eine Entlastungsfunktion, daß Cölestin Christian Flottwell, der als Direktor zugleich die Funktion des Sekretärs wahrnahm, die Aufnahmeurkunden der Neumitglieder an Gottsched schickte und die Weiterverteilung ihm übertrug. Nachdem sie im Dezember 1749 bei ihm eingetroffen waren, versandte Gottsched die Dokumente im Februar des folgenden Jahres.

${ }^{12}$ Vgl. Karl Gustav Helbig: Christian Ludwig Liscow. Ein Beitrag zur Literatur- und Kulturgeschichte des achtzehnten Jahrhunderts. Dresden; Leipzig 1844, S. 61. 
Auch die Gesellschaft der Alethophilen hatte im Gottschedkosmos einen bevorzugten Ort. Mit dem Tod Ernst Christoph von Manteuffels verlor die Gesellschaft ihren Gründer und Organisator und war faktisch nicht mehr existent. Als Symptom dieser Auflösung kann die Tatsache gelten, daß von den Weißenfelser wie auch den Stettiner Alethophilen niemand bereit war, der Bitte Gottscheds um einen Beitrag für die Gedenkschrift auf Manteuffel nachzukommen. Um so erfreulicher dürfte es für Gottsched gewesen sein, daß Johann Laurentius Holderrieder mit einer geschichtlichen Darstellung der Weißenfelser Alethophilen überraschte. Holderrieders Bitte um Begutachtung kam Gottsched unverzüglich nach. Der Text wurde als „ein Zusatz zu dem Manteuffelischen Ehrenmaale“ veröffentlicht, ${ }^{13}$ und Gottsched konnte in der Anzeige mit „Vergnügen“ feststellen, daß die mangelnde Präsenz im Ehrenmaal „einigermaßen ersetzet wird; und die Gesellschaft wenigstens zeiget, daß sie sich ihres Stifters nicht schämet“ ${ }^{14}$

Entwicklung des Korrespondentennetzes Oktober 1749 bis Mai 1750

Der Band enthält 215 Briefe, von denen 17 von Gottsched und drei von Luise Adelgunde Victorie Gottsched stammen. 20 Briefe sind an sie gerichtet, die verbleibenden 175 Briefe sind an Gottsched adressiert.

Die Königsberger Korrespondenten sind auch im vorliegenden Band mit zahlreichen Briefen vertreten, allen voran Cölestin Christian Flottwell, von dem neun Briefe stammen. Durch Gottscheds Anregung wurden wiederum neue Mitglieder in die Königsberger Deutsche Gesellschaft aufgenommen. Flottwell schickte die Mitgliedsurkunden an Gottsched mit Bitte um Weiterleitung, „da sich jedes Mitglied freuen wird, von unserm Vater das Kindesrecht in der Gesellschaft zu erhalten“" (Nr. 23). Er bekräftigte allerdings die Erwartung, daß die Neumitglieder durch Geld- oder Buchspenden und durch literarische Beiträge ein gewisses Engagement für die Gesellschaft aufbringen sollten. Unter diesem Vorzeichen war Friedrich Groschuffs Widmung seiner Horazübersetzung zum Dank für die Aufnahme in die Gesellschaft sehr willkommen. Wie immer unterrichtete Flottwell über Universitäts- und Gesellschaftsangelegenheiten, artikulierte

13 Johann Lorenz Holderrieder: Historische Nachricht von der Weißenfelsischen Alethophilischen Gesellschaft. Leipzig: Johann Friedrich Lankisch, 1750, nicht paginierte Vorrede [S. 1].

${ }^{14}$ Neuer Büchersaal 10/4 (1750), S. 379. 
Buchwünsche und sandte die neuesten Texte der Deutschen Gesellschaft. Die für die Stärkung des Renommees der Gesellschaft unternommene Veröffentlichung der jüngsten Gedichte Gottscheds hatte einen unvorhergesehenen gegenteiligen Effekt. In Luise Adelgunde Victorie Gottscheds mehrfach erwähntem Gedicht an Maria Theresia, das dem zweiten Band der von ihr übersetzten Geschichte der königlichen Akademie der schönen Wissenschaften zu Paris vorangestellt und von den Königsbergern dankbar integriert wurde, wurde neben der Hoheit und Untadeligkeit der Kaiserin auch deren Gegenbild, der schlaue Feind, evoziert, den Neid und Ruhmsucht zum Länderraub treiben. Selbstverständlich wurde kein Name genannt. Aber es ist unmöglich, dabei nicht an den jungen preußischen König und seine Invasion in Schlesien zu denken, und es ist schwer zu erklären, daß den Herausgebern diese Passage entgangen ist. Anders verhielt es sich mit Flottwells „Feinden“, die sofort gegen ihn mobil gemacht und die Behörden informiert haben, die ihm daraufhin „mit Festung v. Relegation“ drohten (Nr. 167). Flottwell hatte die Gedichtsammlung bereits nach Leipzig gesandt, als ihn das Ungemach ereilte. Sofort bat er Gottsched, entweder das gesamte Buch zu unterdrücken oder zumindest das Titelblatt mit der Angabe zur Herausgeberschaft der Königsberger Deutschen Gesellschaft und den Vorbericht, in dem gerade dieses „schöne Gedicht an die Kaiserinn" 15 besonders hervorgehoben wurde, zu entfernen. Beides ist offenbar unterblieben. Dasselbe Mißgeschick, beste Absichten zu hegen und üble Wirkungen zu erzielen, passierte gleich darauf noch einmal. Wie schon lange angekündigt, schickte Flottwell die Einwände, Fragen und Bemerkungen zu Gottscheds Sprachkunst, um auf diese Weise zu beweisen, wie geflissentlich das Werk in der Königsberger Deutschen Gesellschaft studiert worden war. Statt Beifalls und sachlicher Reaktion weckten die Bemerkungen, wie Flottwell von dritter Seite erfuhr, Gottscheds Unwillen. Gottsched hatte in der Sprachkunst nachdrücklich um kritische Lektüre und Verbesserungsvorschläge gebeten, reagierte aber nachgerade gereizt, als diese von allen Seiten eintrafen. Durch die Mitteilung über Gottscheds Verärgerung in „ein Entsetzen gestürzet“, schrieb Flottwell einen flehentlichen Bußbrief, der seine üblichen Bitten um Gottscheds Huld noch ein$\mathrm{mal}$ weit übertraf (Nr. 209). In diesem Brief vom 26. Mai, seinem letzten im vorliegenden Band, berührte er einmal mehr die Münz- und Natura-

${ }^{15}$ Gottsched, Gesammlete Neueste Gedichte, nicht paginierter Vorbericht [S. 2]. 
liensammlung Melchior Philipp Hartmanns, für deren Vertrieb er schon mehrfach bei Gottsched geworben hatte. Von Flottwell über Gottscheds Unterstützungsbereitschaft in Kenntnis gesetzt, wandte sich Hartmann auch selbst mit detaillierten Ausführungen über die Sammlungen an Gottsched. Auch Christian Gabriel Fischer, der einst als Wolffianer aus Preußen verjagt und nach seiner Rückkehr mit einem Lehr- und Publikationsverbot belegt worden war, befaßte sich mit den Beständen. „Zum Zeitvertreib, weil ich nicht müßig seyn kann“, habe er Hartmanns "Sachen, die er verkauffen wil, in Ordnung gebracht" (Nr. 120). Darüber hinaus, so ist von Hartmann zu erfahren, hatte Fischer umfang- und kenntnisreiche Kataloge angefertigt. Dank seiner ausgedehnten Reisen und einem längeren, mit Münzstudien verbundenen Aufenthalt in Rom konnte sich der ehemalige Physikprofessor Fischer kompetente Aussagen über das Münzkabinett und andere Hartmannsche Sammlungen erlauben. Sein Brief, der letzte an Gottsched, schließt mit Reminiszenzen an seinen Aufenthalt in Leipzig. Er bestellte Grüße an Freunde und Gönner und versicherte, daß er, obwohl seine Besuche lange zurücklägen, „das süße Andenken von Dero liebreichen und erbaulichen Umgang, in meinem hertzen, offt erneuere" (Nr. 120).

Seit 1743 unterhielt Christian Heinrich Gütther mit Gottsched einen Briefwechsel, in dessen Zentrum die Verlagssuche und Gestaltungsüberlegungen für sein Buch über den ersten preußischen König stehen. Gottsched hat sich mit nicht nachlassendem Engagement für Gütthers Anliegen verwendet. Mittlerweile stand die Veröffentlichung unmittelbar bevor, doch Gütther trug nach einem Probedruck noch erhebliche Änderungswünsche vor. Für deren Durchsetzung vertraute er weniger auf die Überzeugungskraft seiner Argumente als auf Gottscheds Autorität bei dem Breslauer Verleger Johann Jacob Korn, der das Buch in der Breitkopfschen Druckerei in Leipzig herstellen ließ und während der Messezeiten seinen Buchladen in Breitkopfs Haus zum goldenen Bären unterhielt, ${ }^{16}$ in dem bekanntlich auch das Ehepaar Gottsched residierte.

Von mehreren Seiten war Gottsched über den schlechten Gesundheitszustand seines früheren Lehrers, des angesehenen Königsberger Theologen und Historikers Preußens Michael Lilienthal in Kenntnis gesetzt worden. Lilienthal starb im Januar 1750. Um die Erbschaftsansprüche zu befriedigen, mußte die erlesene Bibliothek Lilienthals zum Bedauern seines Sohnes

16 Vgl. die Buchanzeige in: Leipziger Zeitungen, 13. Oktober 1749, S. 656. 
Theodor Christoph, auch er Theologe und Universitätsprofessor, verkauft werden. Theodor Christoph Lilienthal schickte Auktionskataloge und bat um deren Bekanntmachung.

Mit einem Brief aus Elbing informierte Johann Friedrich Endersch über die Fertigstellung seines neuen Globus, den Gottsched bereits im August 1748 im Neuen Büchersaal angekündigt hatte. Er bat darum, einen mitgeschickten Subskriptionsaufruf bekanntzugeben und bestellte, wie schon mehrfach, Leipziger Zinnasche für seine Arbeiten.

Mehrere schlesische Korrespondenten nahmen die mit Gottscheds Begleitbriefen versehene Einsendung der Urkunden über die Mitgliedschaft in der Königsberger Deutschen Gesellschaft zum Schreibanlaß. Abraham Gottlob Rosenberg, Pfarrer in Mertschütz und seit über 20 Jahren mit Gottsched in vertrautem Umgang, wies eigens darauf hin, daß er Gottsched nach der Rückkehr aus Wien zunächst mit Zuschriften verschonen wollte. Aber Brief und Mitgliedsurkunde geboten eine Danksagung. Rosenberg erinnerte an seine Differenzen mit dem Verleger David Siegert, die zum Abbruch seiner Übersetzung der Predigten Jacques Saurins geführt hatten. Zahlreiche Beschwerden, Nachfragen und Ermunterungen hätten ihn zur Fortsetzung bewogen. Er wollte dem neuen Breslauer Verleger Georg Friedrich Heinrich, der Rosenbergs Rat und Unterstützung gesucht hatte, zu einem erfolgreichen Start auf dem Buchmarkt verhelfen. Rosenberg traute ihm ein autorenfreundlicheres Geschäftsgebaren zu. Heinrich konnte Rosenbergs Brief während der Leipziger Messe Gottsched persönlich überreichen, und vielleicht hat Gottsched, Rosenbergs Empfehlung folgend, dem jungen Verleger eine Orientierungshilfe für seine Präsentation auf dem Messeplatz Leipzig geben können.

Der Waldenburger Pfarrer Nicolaus Kelz hatte Gottsched ausdrücklich um die Vermittlung der Königsberger Mitgliedschaft gebeten, von der er sich offenbar einen Prestigegewinn versprach. Die im Antwortschreiben an Kelz aufgetragenen Grüße veranlaßten den Empfänger Ernst Daniel Adami im unweit von Waldenburg gelegenen Landeshut seinerseits zu einem Schreiben an Gottsched. Er berichtete von seinem Erfolg als Lehrer, der nicht zuletzt der Verwendung der Gottschedschen Bücher zur Beredsamkeit und Dichtkunst zu verdanken sei. Er wünschte, seine Schüler könnten sich vor Gottsched zeigen. Aber eine königliche Verordnung untersage den Absolventen wie allen schlesischen Landeskindern ein Studium außerhalb Preußens.

Der Breslauer Lehrer Carl Benjamin Stieff bedankte sich für die Aufnahme in die Königsberger Deutsche Gesellschaft mit ungarischem Wein. 
Die Gesellschaft sollte Proben seiner Übersetzung des Antilukrez Polignacs erhalten - Gottsched hatte 1748 eine lateinische Ausgabe veranstaltet und die Übersetzung angeregt. Er bat um sorgfältige kritische Prüfung des Textes. Sein Bruder, der Arzt Johann Ernst Stieff, hatte Gottsched Beobachtungen zu Mond- und Sonnenfinsternis eingeschickt und äußerte seinerseits Interesse an der Mitgliedschaft in Königsberg. Sein Wunsch wurde nicht erfüllt. Die Mitgliedschaft wurde offenbar nicht wahllos vergeben, sondern war an bestimmte Kriterien gebunden.

Auch der Brief von Johann Caspar Arlet ist ein Zeugnis für das Ansehen der Königsberger Deutschen Gesellschaft. Arlet wurde von der Mitgliedsurkunde überrascht. Mit seiner Einschätzung, daß Gottsched ihn wegen seiner Bemühung um das Werk Simon Dachs in die Deutsche Gesellschaft vermittelt habe, dürfte er ins Schwarze getroffen haben. Gottscheds Interesse an Gedichten Dachs, die im Rahmen seines Projekts einer Edition preußischer Dichter veröffentlicht werden sollten, ist früh erkennbar. Kommilitonen waren mit seinen Plänen vertraut, und auch der Königsberger Archivar Heinrich Bartsch stellte seine Dachiana Gottsched zur Verfügung, da er „Hoffnung gemachet hat, dieses seines Landsmanns denen wenigsten bekannte Poetische Schrifften zusammen drucken zu lassen ". ${ }^{17}$ Auch wenn Gottsched die Sendung angeblich nicht erhalten hat, besaß er doch eine ansehnliche Sammlung von Werken Dachs. ${ }^{18}$ Seine zahlreichen anderen Unternehmungen haben die Dachedition in den Hintergrund treten und ihre Verwirklichung unwahrscheinlich werden lassen. Um so mehr dürfte es ihn erfreut haben, daß Arlet sich ernsthaft und systematisch der Sache angenommen hat. Wenn auch die Verwirklichung scheiterte, Arlets Bemühung verdankt sich die „bis heute wichtigste Sammlung von Originaldrucken“ Dachs. ${ }^{19}$

Gottscheds langjähriger Korrespondent Adam Bernhard Pantke war schon ein Jahr vor seinen schlesischen Landsleuten Mitglied der Königs-

17 Acta Borussica 2/6 [1731], S. 945; vgl. auch Erleutertes Preußen 5 (1742), S. 198, Nr. 19.

18 Unter Hinweis auf die Aussage in den Acta Borussica erklärte Gottsched, er habe „dieses versprochene Geschenk niemals wirklich erhalten“. Neuer Büchersaal 10/2 (1750), S. 151, Anm. **. Die in seinem Besitz befindlichen Titel Dachs (vgl. Neuer Büchersaal 7/3 [1748], S. 266f.) entsprechen indes genau den Werken, die ihm zugeschickt wurden; vgl. Acta Borussica 2/6 (1731), S. 945.

19 Vgl. Alfred Kelletat: Nachwort. In: Kelletat (Hrsg.): Simon Dach und der Königsberger Dichterkreis. Stuttgart 1986, S. 331-420, 406. 
berger Deutschen Gesellschaft geworden, auch er durch Gottscheds Vermittlung. Gelangten sonst Klagen aus Königsberg über Mangel an Resonanz seitens der Neumitglieder an Gottsched, so beklagte Pantke, daß seine Schreiben nach Königsberg unbeantwortet blieben. Pantke dankte für Gottscheds wohlwollende Anzeige seiner Übersetzung der Begebenheiten Neoptolems, die von Gottsched gefördert worden war. Sein Brief enthielt das soeben fertiggestellte Gedicht auf den hundertsten Todestag Ludwigs von Anhalt-Köthen, des Gründers der Fruchtbringenden Gesellschaft. Das Gedicht erschien ohne Verfassernamen, aber Gottsched entsprach der Bitte seines langjährigen Korrespondenten und nannte den Autor in der Anzeige des Textes. Mehr noch, er präsentierte ihn geradezu als Qualitätsmerkmal: „Der seiner schönen Poesie wegen berühmte Hr. M. Pantke in Schlesien ist der Urheber dieses Gedichtes. “20

Gottsched hatte seine Forderung, antiquarische Aktivitäten nicht nur auf exotische oder antike Monumente auszurichten, sondern auch die heimische Vergangenheit zu berücksichtigen, mit einem Beitrag über die preußische Marienburg, den einstigen Sitz des Deutschen Ordens, exemplifiziert. Die Darstellung im Neuen Büchersaal beruhte auf Ausführungen des Danziger Gymnasialprofessors und hervorragenden Kenners der preußischen Geschichte Michael Christoph Hanow. In seinen Briefen beanstandete Hanow eine Reihe von Wiedergabefehlern beim Druck seines Textes und stellte klar, daß er für eine ausführlichere Beschreibung der Marienburg nicht zur Verfügung stehe. Als Gründungsmitglied der Danziger Naturforschenden Gesellschaft erinnerte er an Gottscheds Bereitschaft, sich für den Schriftenband der Gesellschaft zu verwenden. Die Gesellschaft hatte den Band im Selbstverlag veröffentlicht und Gottsched gebeten, nachdem der Verkauf nicht den Erwartungen entsprochen hatte, Bernhard Christoph Breitkopf für die Übernahme des beträchtlichen Restbestandes zu gewinnen. Auch ihr Sekretär Gottfried Reyger wandte sich in dieser Angelegenheit erneut an Gottsched, der zu seinem Bedauern nur Breitkopfs Absage übermitteln konnte.

In der Oberlausitz hatte sich eine gelehrte Gesellschaft konstituiert, die seit 1748 ihre Beiträge in einem eigenen Periodikum veröffentlichte. Die Zusendung durch den Diakon Gottlob Friedrich Gude, einen ihrer produktivsten Beiträger, war mit der Erwartung einer Rezension im Neuen

${ }^{20}$ Neuer Büchersaal 10/5 (1750), S. 473 f., 473. 
Büchersaal verbunden. Gottscheds Anzeige war wohlwollend, enthielt aber kaum mehr als das Inhaltsverzeichnis. Gude hatte eine einläßliche Beschäftigung erbeten. Daß keine weiteren Briefe vorliegen, ist möglicherweise Indiz einer enttäuschten Erwartung.

Johann Daniel Overbeck hatte die Hoffnung, seine Stelle als Subrektor in Lübeck mit einer akademischen Position in Helmstedt zu vertauschen, wofür sich Gottsched vergeblich eingesetzt hatte, inzwischen aufgegeben. Aus diesem Grund verzichtete er auf den Plan, seine Vergilübersetzung dem über Helmstedt verfügenden Braunschweiger Herzog Carl I. zu widmen. Als Widmungsempfänger setzte er stattdessen Gerlach Adolph von Münchhausen, den Kurator der Universität Göttingen, ein. Es fällt schwer, Overbecks Versicherung, daß er bei dieser Umwidmung ,auf Eigennutz gar nicht habe sehen können“, ganz ernst zu nehmen. Nachdem Overbeck Gottscheds Einwand, eine Vorrede mit seinem Namen könne der Aufnahme des deutschen Vergil eher hinderlich sein, geradezu bekenntnishaft zurückgewiesen hatte, stellte Gottsched einen Text in Aussicht. Overbeck prophezeite, daß dem „Hrn Verleger daraus nicht geringer Vortheil fließen“ werde (Nr. 168).

Nach einem Besuch Gottscheds in Leipzig dankte Theodor Johann Quistorp für die Gastfreundschaft und bat um die diskrete Entgegennahme eines Briefes, der an ihn, Quistorp, nach Leipzig geschickt worden, aber nicht rechtzeitig eingetroffen war. Quistorp hatte seit 1742 mit großem Enthusiasmus mit Gottsched korrespondiert, er führte dichtungstheoretische Auseinandersetzungen im Sinne Gottscheds, seine Dramen fanden Aufnahme in Gottscheds Deutsche Schaubühne, weitere Texte wurden im Neuen Büchersaal veröffentlicht, zuletzt das „Gespräch im Traume mit dem Hrn. von Canitz, über die neumodische hieroglyphische Schreibart" ${ }^{21}$ Der Text unter dieser Versuchsanordnung, in dem der im Traum erscheinende weltmännische Dichter Friedrich Rudolph Ludwig von Canitz die moderne Dichtart vornehm-belustigt zurückweist, ging auf eine Anregung Gottscheds zurück, für deren Ausführung Gottsched schon Friedrich Melchior Grimm gewinnen wollte (Band 13, S. 173f.). Es scheint die letzte poetische und poetologische Arbeit Quistorps überhaupt gewesen zu sein. Auf jeden Fall gelangte nichts mehr an Gottsched, ${ }^{22}$ und auch der Briefwechsel endet

${ }^{21}$ Neuer Büchersaal 9/4 (1750), S. 301-320.

22 Gottsched kündigte im Neuen Büchersaal noch eine historisch-juristische Veröffentlichung Quistorps an, die ihm im Manuskript zugänglich gemacht worden war, die aber augenscheinlich nicht erschienen ist; vgl. Neuer Büchersaal 9/4 (1750), S. 371-374. 
mit dem vorliegenden Band. Schon seit längerem klagte Quistorp über die berufliche Belastung durch den „Advocatenkram“ (Band 12, S. 452), der die schönen Wissenschaften an den Rand dränge und auch zur Korrespondenz keine Zeit lasse. Die Verpflichtungen nahmen indes eher zu, 1750 wurde er zum Ratsherrn in Wismar erwählt, die Balance zwischen Amtsarbeit und schöngeistiger Neigung war endgültig zu Ungunsten der letzteren aufgegeben. Immerhin wurde Quistorp als Mitglied der von Gottsched gegründeten Gesellschaft der freyen Künste geführt.

Jean Henri Samuel Formey, Sekretär der Berliner Akademie der Wissenschaften, war seit deren Gründung Mitglied der Berliner Alethophilengesellschaft. Er erfreute sich der besonderen Gunst Ernst Christoph von Manteuffels und stand auch nach dessen Abschied aus Berlin mit dem Reichsgrafen in kontinuierlicher Briefverbindung. Auf Gottscheds Bitte um einen Text für die Gedenkschrift auf Manteuffel hatte Formey unverzüglich reagiert. Nachdem der angekündigte Veröffentlichungstermin längst verstrichen war, erkundigte sich Formey nach dem Verbleib und erbat seinen Beitrag zurück. Mit der Antwort auf diesen Brief konnte Gottsched das Manteuffelsche Ehrenmaal an Formey verschicken, „dazu Dieselben einen so schönen Beytrag gethan haben“" (Nr. 126). Wie üblich informierte man sich über eigene Publikationen, Formey verwies auf seine Zeitschriftengründungen. Gottsched bat um die Veröffentlichung einer von ihm verfaßten Rede im Jahrbuch der Akademie. Daß weder der Inhalt des nach Gottscheds Auskunft nur handschriftlich vorliegenden Textes noch dessen Anlaß ermittelt werden konnten, zeigt einmal mehr, daß trotz gut dokumentierter Abläufe des Leipziger Universitätsgeschehens beträchtliche Lücken in Rechnung zu stellen sind. Formey lehnte die Aufnahme des Textes ab, angeblich aus Platzgründen. Seine geheimnisvolle Warnung vor Veröffentlichungen über das preußische Herrscherhaus lassen aber einen anderen Grund erahnen. In seiner Rezension des Akademiejahrbuchs von 1748 hatte Gottsched einen Aufsatz zur Geschichte Brandenburgs gemaßregelt, offenbar ohne zu wissen, daß der Text mit den beanstandeten Äußerungen über frühere preußische Herrscher vom König selbst, von Friedrich II., stammte. Daß diese Rezension Gottscheds Ruf in Berlin beschädigt hat, ist auch am Brief Johann Christoph Kreuschners zu erkennen, der sich in aller Vorsicht danach erkundigte, ob Gottsched wisse, was er ge$\tan$ habe. Kreuschner, der Sohn von Gottscheds verehrtem Königsberger Lehrer und Freund Johann Heinrich Kreuschner, hatte Gottsched bei dessen Königsbergbesuch im Sommer 1744 kennengelernt. In seinen Briefen, 
auch in dem des vorliegenden Bandes, erbat er von Gottsched Zeugnisse und Unterstützung für die Auszahlung von Stipendien. Gottsched erfüllte die Bitten. Daß die Korrespondenz mit dem vorliegenden Brief endet, könnte mit einem Mißgeschick zusammenhängen. Dem Brief lag ein weiterer Brief bei, der von Kreuschners Angehörigen stammte, für Frau Gottsched bestimmt war und von Kreuschner weitergeleitet werden sollte. Nur war der Auftrag zur Weiterleitung schon Monate oder Jahre zuvor erteilt worden, Kreuschner konnte sich nicht entsinnen. Er hatte den Brief, offenbar ramponiert, unter seinen Papieren gefunden. Den wortreichen Entschuldigungen zum Trotz: Bei den Gottscheds könnte der Eindruck entstanden sein, daß sie für Kreuschner, soweit es nicht seine eigenen Belange betraf, wenig bedeuteten.

Daniel Wilhelm Triller, seit 1749 Inhaber einer Medizinprofessur in Wittenberg, hat sich, wie schon erwähnt, in seinem Brief zum Projekt der Molièreübersetzung geäußert.

Von Wittenberg aus eröffnete auch Georg Matthias Bose die Korrespondenz. Der Wittenberger Professor für Physik, namhafte Elektrizitätsforscher und Sproß einer prominenten Leipziger Kaufmannsfamilie hatte in Leipzig und andernorts Erkundigungen eingezogen, da ,in dem gantzen orthodoxen Wittenberg die Rede ging, Ew: HochEdelGebohrnen, wären zur römischen Kirchen übergetreten“. Durch die Falschbehauptungen sah Bose in Gottsched einen Leidensgenossen, mit dem er, Bose, ,in eine Creutzträger Claße" versetzt war (Nr. 13). Wie Gottsched infolge der Wienreise und der kaiserlichen Gunsterweise war Bose durch Sympathiebekundungen des Papstes Benedikt XIV. in Verruf geraten. Bose hatte dem wissenschaftsfreundlichen Papst Veröffentlichungen geschickt, einen Dankesbrief erhalten und dadurch den Unmut der Kollegen von der theologischen Fakultät auf sich gezogen, die darin eine Anbiederung an Rom erkennen wollten. Nach seiner Überzeugung war ihr Vorgehen in persönlichen Verstimmungen begründet. Boses Briefe schildern die Auseinandersetzungen, die öffentlich und unter Einbeziehung des Oberkonsistoriums geführt wurden. Der für Toleranz plädierende Lutheraner Bose wollte sich nicht einschüchtern lassen und war trotz eines Klimas der Verdächtigungen bereit, die Gedenkschrift auf den kaiserlichen Kanzler von Böhmen Friedrich August von Harrach mit einer Ode zu bereichern. Allerdings sollte sein Name nicht genannt werden: Offenbar wollte er vorerst keine neuen Angriffsflächen bieten.

Aus Wittenberg, seinem Studienort, stammte auch der erste Brief des Magisters Immanuel Friedrich Gregorius. Ermutigt von Gottscheds wohl- 
wollenden Anzeigen seiner Veröffentlichungen, wollte er Mitglied „der weltberühmten deutschen Gesellschaft die sich unter Eurer Hochedelgebohrnen Magnificenz hohen Aufsicht befindet" werden, bedauerte aber, daß nach seinen Kenntnissen Fremden kein Zugang gewährt würde (Nr. 119). Nichts davon stimmte. Die Gesellschaft war gänzlich inaktiv, Gottsched seit mehr als einem Jahrzehnt ausgetreten, und tätige auswärtige Mitglieder waren in der Blütezeit der Gesellschaft allenthalben gefragt. Man hätte gern gewußt, woher Gregorius seine Informationen bezog. Wie aus späteren Briefen hervorgeht, verwies ihn Gottsched wie in allen ähnlichen Fällen an die Deutsche Gesellschaft in Königsberg.

Christoph Friedrich Geiger hatte 1746 den Briefkontakt zu Gottsched aufgenommen, weil er aus seiner Position als Prinzenerzieher am Bernburger Hof entlassen worden war und eine akademische Karriere in Angriff nehmen wollte. Er konnte seinerzeit in Bernburg verbleiben, aber inzwischen wiederholte sich die Ausgangslage. Geiger wandte sich erneut an Gottsched und sandte den Druck seiner Gedancken von dem Bücherschreiben Der Gelehrten - ein Plädoyer dafür, die Eignung zum akademischen Lehramt nicht von der Zahl der Veröffentlichungen, sondern vom pädagogischen Erfolg im Umgang mit Standespersonen abhängig zu machen. Gottsched druckte diese auf Geigers Person zugeschnittene Qualifikationsbeschreibung im Neuen Büchersaal wieder ab. Auch in den folgenden Monaten setzte sich Gottsched intensiv für Geiger ein, bat Friedrich Heinrich von Seckendorff, dem er Geiger im April 1750 in Meuselwitz persönlich vorstellte, um Fürsprache an mehreren Höfen, beherbergte ihn zeitweise in Leipzig und vertraute ihm, nachdem Seckendorff nichts von sich hören ließ und auch andere Optionen nicht verwirklicht wurden, die Stelle eines Hofmeisters bei dem Grafen Hans Ernst von Dyherrn im schlesischen Osten an. In seinem letzten Brief des vorliegenden Bandes kündigte Geiger seine bevorstehende Abreise nach Schlesien an.

Die Briefe des Dresdner Konferenzministers Joseph Anton von Wackerbarth sind wie immer knapp, lassen aber gleichwohl erkennen, wie bedeutsam dieser verläßliche Korrespondent am Dresdner Hof für Gottsched war. Die vielbeachteten kaiserlichen Geschenke gelangten nach ihrem Transport auf diplomatischen Kanälen an seine Adresse und wurden unter seinem Siegel sicher nach Leipzig weitergeleitet. An ihn adressierte Gottsched das für den Kurprinzen bestimmte Exemplar des Manteuffelschen Ehrenmaals. Oberkonsistorialpräsident Christian Gottlieb von Holtzendorff ist mit seiner Erwiderung auf die Neujahrswünsche Gottscheds vertreten - 
Zeichen einer Kontaktpflege, die Gottsched auch jenseits konkreter Anliegen nicht unterließ.

Engelbert Heinrich Schwartze, ehemaliger Leipziger Student der Rechtswissenschaften, mittlerweile Gerichtshalter des Reichsgrafen Heinrich von Bünau, hatte im Mai 1749 seine Schrift zur Monadenlehre an Gottsched, einen seiner "größten Lehrmeister im Denken“" (Band 14, S. 412), gesandt und um eine Rezension seines Beweises von den einfachen Dingen gebeten, der gegen Johann Heinrich Gottlob Justis monadenkritische und auch von Gottsched mißbilligte preisgekrönte Untersuchung der Lehre von den Monaden gerichtet war. In seinem Antwortbrief ließ Gottsched der Schrift offenbar hohes Lob zuteil werden. Da er auch Schwartzes Schreibart rühmte und ihn zu einer Reform der juristischen Diktion ermunterte, reagierte Schwartze nahezu euphorisch. Er betonte, auch seine Ausdrucksfähigkeit in der deutschen Sprache nur Gottsched zu verdanken (Nr. 10, so schon Band 14, S. 491 f.), nahm dessen Anregung auf, bat Gottsched um die Unterstützung für das Projekt seiner geplanten Monatsschrift und erkundigte sich neuerdings nach Gottscheds Rezension seines Beweises von den einfachen Dingen. Die erschien wenig später. Gottsched wies auf den Unterschied zur Leibnizschen Monadenlehre hin, wollte den Verfasser „eher für einen Atomisten, als Monadisten halten", bezweifelte den Neuigkeitswert vieler Argumente und schloß mit dem eher vernichtenden Satz: „Wir müssen aber allerdings die Bemühung des Herrn Verfassers loben, daß er nach so vielen Versuchen, auch seine Gedanken von den einfachen Dingen, der gelehrten Welt hat bekannt machen wollen. "23 Weitere Briefe Schwartzes liegen nicht vor, auch seine Monatsschrift wurde nicht veröffentlicht.

Der Dresdner Arzt Johann Christoph Neide, ein enger Freund Ernst Christoph von Manteuffels, bestätigte nach Eingang der Gedenkschrift auf den Grafen die Treffsicherheit des Kupferstichs bzw. des zugrundeliegenden Porträts.

Einen interessanten Einblick in den Buchbesitz und ebenso in die Vorstellung einer anzustrebenden enzyklopädischen Bibliothek vonseiten eines Nichtgelehrten erlaubt der Brief des Porzellanmalers der Meißner Manufaktur Johann Christian August Birnbaum. Woher Birnbaum die Kenntnis der von ihm aufgeführten Titel bezogen hat, ist dem Brief nicht zu entnehmen. Merkwürdig bleibt, daß sich der Absender mit der Bitte um Beratung

${ }^{23}$ Neuer Büchersaal 9/1 (1750), S. 79-81. 
ausgerechnet an Frau Gottsched wandte, die tatsächlich, wie der Antwortvermerk zeigt, reagiert hat. Ebenso merkwürdig bleibt, daß das einzige abfällige Urteil über eines der von ihm genannten Werke ausgerechnet dem englischen Zuschauer galt, einer Übersetzung des von Birnbaum wegen ungemeiner Gelehrsamkeit und vollkommenen Geschmacks verehrten Ehepaares Gottsched. Gewiß, die Übersetzung war anonym erschienen, aber Gottsched selbst hatte die Namen der Übersetzer bekanntgegeben, ${ }^{24}$ das literarisch informierte Publikum dürfte Bescheid gewußt haben. Will man nicht Ranküne unterstellen, bestätigt dieses Urteil indirekt die Unzugehörigkeit des Verfassers zur Respublica litteraria.

Die Leipziger Lebenswelt des Ehepaares Gottsched mit ihrer Alltagsgestaltung, Besuchen von Freunden und Kollegen, dienstlichen und anderen Verpflichtungen bleibt in der Korrespondenz aus naheliegenden Gründen unterbelichtet, die unmittelbaren Kontakte erübrigen in der Regel den schriftlichen Austausch. Insofern sind die im vorliegenden Band enthaltenen kurzen Schreiben an Frau Gottsched aus dem Leipziger Umfeld eine erhellende Ausnahme. Die Schreiben des Geschichtsprofessors Christian Gottlieb Jöcher, dessen Name mit dem von ihm veröffentlichten Gelehrtenlexikon eine dauerhafte Verbindung eingegangen ist, gewähren einen Einblick in den freundlich-verbindlichen Umgangston in der Kollegenschaft. Der ebenso kurze Brief von Wolfgang Georg Welck, Beamter in der Oberpostdirektion, wirft Licht auf eine Person, die in der bisherigen Korrespondenz unbekannt ist und auch in den gedruckten Briefen der Frau Gottsched nicht genannt wird. Aber daß die Gottschedin das politisch nicht unverfängliche Widmungsgedicht für die Kaiserin Welck vor der Drucklegung mit der Bitte um Diskretion zur Lektüre übergab, spricht für einen vertrauten Umgang mit dem späteren Leipziger Oberpostdirektor. Die Gegenprobe, ein Blick in die familiäre Korrespondenz Gottscheds mit seiner Nichte nach dem Tod seiner Gemahlin, bestätigt diese Sicht und zeigt zugleich, daß diese Verbindung Bestand hatte: Am 28. November 1764 schrieb Gottsched an die Nichte Victoria Eleonora Grohmann: „Jetzo gehe ich H.n Hofr. Welken zu besuchen ... Am Sonntage war ich auch bey Ihm". 25

24 Vgl. Neuer Büchersaal 1/6 (1745), S. 539.

${ }^{25}$ Leipzig, UB, 0343d, Bl. 41-42, 42v. Welck gehörte als Candidatus Juris schon Anfang der Dreißigerjahre zu Gottscheds engerem Bekanntenkreis und verkehrte wie dieser im Salon der Christiana Mariana von Ziegler; vgl. Andrew Talle: „Ein Ort zu 
Johann Gottlieb Biedermanns als Einladungsschrift zu einem Freiberger Schulakt erschienene Schrift De Vita Musica ist wie wenige derartige Schulprogramme in Erinnerung geblieben, weil Johann Sebastian Bach in seinen letzten Lebensmonaten an der Auseinandersetzung um diesen Text mit seiner vermeintlichen Geringschätzung der Musik beteiligt war. In den Biographien und Dokumentensammlungen über Bachs Leben hat sie infolgedessen einen sicheren Platz. Biedermann wollte, wie er im Brief an Gottsched bekannte, im Streit um die fachlichen Prioritäten im Unterrichtsplan den Vorrang der schönen Wissenschaften vor der Musik behaupten, der sein Rivale, der Freiberger und spätere Leipziger Thomaskantor Johann Friedrich Doles, den Vorzug gab. Mit Doles wollte Biedermann nach dem wegen des Textes entstandenen heftigen öffentlichen Streit nicht mehr zusammenarbeiten, zugleich aber dem Wunsch des Freiberger Magistrats nach einer musikalisch gestalteten Schulfeierlichkeit Rechnung tragen. Er bat Gottsched um eilige Zusendung eines vorliegenden Singspiels und verwies auf die Fähigkeit seiner Schüler zur Bewältigung auch anspruchsvoller Kompositionen. Ob Gottsched den Wunsch erfüllen konnte, ließ sich nicht feststellen. Er setzte sich indes für Biedermann ein, indem er kurz nach Empfang des Briefes im Neuen Büchersaal gegen anderweitige Behauptungen erklärte, daß Biedermann als Musikfeind zu diskreditieren eine böswillige Unterstellung sei.

Kein Korrespondent faßte so eindrücklich in Worte, wie sehr ihn das Gerücht von Gottscheds Konfessionswechsel verstört und das Dementi folglich erleichtert habe, wie der Zwickauer Rektor Christian Clodius. Als langjähriger Freund Gottscheds war er mit dessen Gesinnung vertraut und hätte eine Konversion nur als Heuchelei verstehen können. Als Freund konnte er es sich auch erlauben, Gottsched mit Spendenwünschen für die Zwickauer Ratsschulbibliothek zu strapazieren. Allerdings war Clodius auch andernorts, wenn es um die Sammlungen der Bibliothek ging, nicht zurückhaltend. Clodius wies auf die Veröffentlichung eines in Zwickau tätigen Hofmeisters hin, die unfreundliche Bemerkungen über Gottsched enthielt. Dieselbe Person hat sich erstaunlicherweise gleichzeitig an Gottsched gewandt und Auskunft für ein geplantes Buch über zeitgenössische gelehrte Frauen erbeten. Allerdings mit einem Pseudonym und selbstverständlich

studiren, der seines gleichen nicht hat" - Leipzig um 1730 in den Tagebüchern des Königsberger Professors Christian Gabriel Fischer. In: Stadtgeschichte Jahrbuch 2008, S. 55-138, 103. 
ohne die Veröffentlichung zu erwähnen. Bei genauerer Betrachtung stellte sich heraus, daß der Hofmeister auch ein begeisterter Klopstockanhänger war. Die Konstellation hat Seltenheitswert, und zu den Überraschungen gehört, daß dieser Johann Nathanael Reichel in Zwickau Jahre später dem Kreis der Gottschedfreunde und -korrespondenten angehörte, und dies zu einer Zeit, in der die Fraktionsbildung in ästhetischen Belangen auf Konfrontation ausgerichtet und Integration nicht vorgesehen war.

Friedrich Heinrich von Seckendorff, der auf seinem Gut in Meuselwitz bei Altenburg lebende langjährige kaiserliche General, hatte die Gottscheds mit Empfehlungsschreiben für Wien ausgestattet. Er erhielt deshalb alsbald noch von Wien aus von Frau Gottsched einen Bericht, der indes auf die Begegnung mit der Kaiserfamilie reduziert war. Weitere Details sollten in einer persönlichen Begegnung zur Sprache gebracht werden - die Gottscheds waren bekanntlich regelmäßig in Meuselwitz zu Gast. Der folgende intensive Briefwechsel enthält Reminiszenzen an Seckendorffs Bekannte am Wiener Hof. Seckendorff schwärmte von der verwitweten Kaiserin Elisabeth Christine von Braunschweig-Wolfenbüttel, der „Quint Essenz von allen großen frauen" (Nr. 26), rühmte die Gelehrsamkeit und Friedensliebe des von seinen Beratern in die Irre geleiteten Wittelsbacher Kaisers Karls VII. und sah in der den Gottscheds gewährten Audienz den Beleg dafür, daß die Übergriffe gegen die ungarischen Protestanten vom katholischen Klerus zu verantworten und nicht der Kaiserin anzulasten sind. Auf Seckendorffs Anfrage konnte Gottsched einen detaillierten Bericht über die mysteriöse Entführung und Rückkehr des katholischen Konvertiten Clemens Romani geben, der in Leipzig als italienischer Sprachlehrer tätig war. Gottsched sorgte sich weiterhin um die Sammlung der Reden und Gedichte, die anläßlich der goldenen Hochzeit des Ehepaares Seckendorff entstanden waren. Eine Veröffentlichung kam nicht zustande. Auch Gottscheds Vorschlag einer Gedenkmedaille wurde nicht in die Tat umgesetzt. Gottsched konnte Seckendorff über einschneidende Umbesetzungen politischer Ämter am Ansbacher Hof befragen und seine Sorgen über vermeintliche Konversionen fürstlicher Personen zum Katholizismus vortragen. Die Gerüchte erwiesen sich als falsch. Auch die in Leipzig kolportierte Annahme, daß Seckendorff im Sommer ein kaiserliches Heer in Italien kommandieren würde, konnte der Feldmarschall dementieren. Dessen einzige größere Unternehmung im Frühjahr 1750 blieb eine Reise an Höfe in Franken, Württemberg und andernorts, während der er sich, wie schon erwähnt, auf Gottscheds nachdrückliche Bitte hin für eine akademische An- 
stellung Christoph Friedrich Geigers einsetzte. Gottsched kümmerte sich um Seckendorffs Buchwünsche und schickte seine neuen Veröffentlichungen, darunter das Ehrenmaal Manteuffels. Die Lektüre bewog Seckendorff zu einer ganz speziellen Reaktion. Er erinnerte sich an eine Bemerkung, die der Prinz Eugen bei der Entgegennahme seiner Lebensbeschreibung ihm gegenüber gemacht hatte: Wenn alles berichtet würde, so Eugen von Savoyen, enthielte sie viele Narrheiten - „Coujonneries“ (Nr. 134). Seckendorff dürften die Zechgelage mit königlichen Häuptern in der Société des antisobres oder die gefährliche und gut honorierte Spionagetätigkeit für das Haus Habsburg vor Augen gestanden haben, in die beide, Manteuffel und er, eingebunden waren. ${ }^{26}$ Auf Gottscheds interessierte Nachfrage wiegelte Seckendorff ab. Intimitäten dieser Art sollten natürlich nicht öffentlich gemacht werden, und er dekretierte: "genug Prinz Eugen und Graf Manteuffel waren beÿde in ihrem Handwerck gute Meister" (Nr. 158).

Es wurde schon erwähnt, im April 1750 stattete das Ehepaar Gottsched gemeinsam mit Christoph Friedrich Geiger Meuselwitz einen Besuch ab. Die Einladung erging Anfang April. Am 11. April bedankte sich Luise Adelgunde Victorie Gottsched bei Clara Dorothea von Seckendorff, der Gemahlin des Feldmarschalls. Die Gastgeberin hatte offenbar als Attraktion des bevorstehenden Aufenthalts das Erlebnis eines guten Predigers in Aussicht gestellt. Frau Gottsched nahm das zum Anlaß, ihre Vorstellung von der Aufgabe und Praxis eines Landpredigers zu entwickeln.

Aus Meuselwitz, seinem Geburtsort, in den er nach dem Theologiestudium in Leipzig und Göttingen zurückgekehrt war, um dort in den folgenden Jahren als Diakon zu wirken, schickte auch Jacob Christian Hecker einen Beitrag für die Seckendorffsche Jubiläumsschrift an Gottsched. Er bot die Mitarbeit an Gottscheds Zeitschrift an. Ob Gottsched das Angebot angenommen hat, muß offenbleiben, da weitere Briefe fehlen.

Der Briefwechsel mit Caroline von Seckendorff, der Frau des Altenburger Kanzlers Ernst Friedrich von Seckendorff, wurde von L. A. V. Gottsched

\footnotetext{
26 Vgl. Anne-Simone Rous: Der Weinkeller als Schlachtfeld. Die „Société des antisobres“ als militärisch-politischer Geheimbund zwischen Sachsen und Preußen. In: Gundula Gahlen, Daniel Marc Segesser, Carmen Winkel (Hrsg.): Geheime Netzwerke im Militär 1700-1945. Paderborn 2016, S. 25-52, 38; Hans Jochen Pretsch: Graf Manteuffels Beitrag zur österreichischen Geheimdiplomatie von 1728 bis 1736. Ein kursächsischer Kabinettsminister im Dienst des Prinzen Eugen von Savoyen und Kaiser Karls VI. Bonn 1970.
} 
unterhalten. Caroline von Seckendorff hatte wegen seit Monaten ausbleibender Briefe befürchtet, in Vergessenheit geraten zu sein, zumal „plusieurs personnes" (Nr. 19) den Wechsel der Gottscheds nach Wien prophezeit hatten. Um so größere Freude bezeigte sie über die Briefe der Gottschedin.

Carl Gottlob Springsfeld sandte seine Abhandlung über das Karlsbad, die Gottsched nach seinem Besuch des Ortes besonders interessiert haben dürfte. Springsfelds Bemerkungen über das Programm, mit dem sein ehemaliger Weißenfelser Kollege und erfolgreicher Konkurrent um eine Medizinprofessur in Wittenberg Daniel Wilhelm Triller zur Antrittsrede für eben diese Universitätsstelle einlud, verraten bereits ein besonderes Interesse an Trillers Ausführungen und insbesondere an der Emendation eines medizinisch relevanten Begriffs in einem Text Suetons. Springsfeld war von Trillers Vorschlag zunächst überzeugt, vermutete aber, daß Triller beim Studium der nachgelassenen Manuskripte und Schriften des Arztes und Medizinhistorikers Thomas Reinesius auf seine Konjektur gekommen war. Im Ergebnis weiterer Untersuchungen hielt Springsfeld indes Trillers Texteingriff für verfehlt und begründete das im April 1750 in einer Epistola Medico-Critica ad ... Danielem Guilielmum Trillerum ... Super Loco Quodam Suetonii. Triller reagierte gereizt, es kam zu einem heftigen Schlagabtausch. ${ }^{27}$ Weitere Bemerkungen über Triller, Ereignisse im Intellektuellenmilieu, seine (vergebliche) Bemühung um den Leipziger Magistertitel und die Erfolge als Karlsbader Bäderarzt füllen Springsfelds Briefe. Springsfeld trug den Wunsch Johann Christian Messerschmids, für die periodische Sammlung kleiner exegetischer Beiträge über Gottsched Kontakte nach Königsberg zu erhalten, an Gottsched heran, bevor sich Messerschmid selbst aus Weißenfels in dieser Angelegenheit an Gottsched wandte. Auch die Nachricht von der ehemaligen Alethophilischen Gesellschaft zu Weißenfels, über die ihr Verfasser Johann Laurentius Holderrieder, inzwischen in Naumburg ansässig, mit Gottsched korrespondierte, wurde von Springsfeld zuvor angekündigt. Als einstiger Sekretär der Weißenfelser Alethophilen war Springsfeld im Besitz des Protokollbuchs der Gesellschaft und konnte Holderrieder mit den erforderlichen Informationen ausstatten.

Gottscheds Reaktion auf sein nicht überliefertes erstes Schreiben hat den Weimarer Gymnasiasten Johann August Schlettwein zu einem weiteren

27 Vgl. Friedrich Börner: Nachrichten von den vornehmsten Lebensumständen und Schriften Jeztlebender berühmter Aerzte und Naturforscher in und um Deutschland. Band 3. Wolfenbüttel: Johann Christoph Meißner, 1753, S. 170-172. 
Brief und zur Zusendung einer theologischen Disputation über die Sünde wider den heiligen Geist ermutigt. Die Bitte um eine Stellungnahme scheint Gottsched nicht erfüllt zu haben, so daß die Korrespondenz mit dem späterhin bedeutendsten deutschen Physiokraten Schlettwein mit dem vorliegenden Brief schon wieder beendet ist.

Die Gothaer Herzogin Luise Dorothea ist mit einem Dankesschreiben für die Gedenkschrift auf Ernst Christoph von Manteuffel vertreten. Die Herzogin hatte über Jahre einen intensiven Briefwechsel mit Manteuffel geführt, in dem Manteuffel auch Gottsched und andere Gelehrte ihrer Aufmerksamkeit empfahl. Auch Johann Adam Löw, der die Position eines Gothaer Generalsuperintendenten nicht zuletzt Manteuffel verdankte, erwähnte das Manteuffelsche Ehrenmaal und dankte Gottsched für weitere Buchsendungen.

Seit 1746 unterhielt Johann Daniel Heyde einen regelmäßigen Briefwechsel mit seinem Lehrer Gottsched, in dem Übersetzungsfragen, Publikationen, Familiäres oder auch die Bemühung um Handschriften für Gottscheds in Aussicht gestellte Literaturgeschichte zu erwähnen sind. Über Heyde wurden weitere Kontakte in und um Gera gepflegt oder vermittelt. Im Sommer 1749 stattete das Ehepaar Gottsched den Geraern einen Besuch ab, in dessen Folge sich die Korrespondenz noch einmal verdichtete. Nachdem Heyde den Kaufmann David Gottfried Schöber bewegen konnte, aus seiner kostbaren Sammlung Handschriften und seltene Drucke für Abschriften zur Verfügung zu stellen, die Heyde im Auftrag Gottscheds anfertigen ließ, sandte Schöber selbst ein von ihm veröffentlichtes Gesangbuch (Band 14, Nr. 158) an Gottsched und erörterte weitere Veröffentlichungspläne. Die beiden Briefe des vorliegenden Bandes, mit denen die Korrespondenz bereits endet, widmen sich demselben Thema: Schöber hatte noch Korrekturen am Gesangbuch vorgenommen und ein drastisch papstfeindliches Lutherlied von der Veröffentlichung ausgeschlossen. Konfessionelle Polemik mit Gesangbuchtexten in die Gemeinden zu befördern, entsprach nicht mehr dem Geist der Zeit.

Als Superintendent und Konsistorialassessor hatte Johann Christoph Pfeiffer an einer Visitation der herrnhutisch gepägten Brüdergemeine in Ebersdorf teilgenommen. Seine Vertrautheit mit Sprache und Theologie der von Nicolaus Ludwig von Zinzendorf geprägten Gemeine veranlaßten Gottsched, eine gegen die Herrnhuter gerichtete Komödie, Der entlarvte Herrnhuter, Pfeiffer zur Lektüre und gegebenenfalls zur Überarbeitung zu übergeben (Band 14, S. 414). Pfeiffer nahm sich der Sache an und konnte 
einen Verleger für den Text gewinnen. Mit dem vorliegenden Band distanzierte sich Pfeiffer jedoch von der geplanten Veröffentlichung, da durch die Darstellung zwar die Herrnhuter der Lächerlichkeit preisgegeben, aber auch die „wichtigsten und heiligsten Religions Wahrheiten“ beschädigt werden könnten. Das freundschaftliche Verhältnis zu Gottsched kommt im Vorschlag einer gemeinsamen Reise zur Familie Jerusalem in Wolfenbüttel (Pfeiffers Schwester und Schwager) zum Ausdruck. „Wir machten nebst meiner Frau gerade eine volle Fuhre aus". Pfeiffer nannte alsbald auch einen Reisetermin und fügte die zeitlos gültigen Worte hinzu: „Soll sich die Zeit nach unserer Arbeit richten, so haben wir immer nicht Zeit“ (Nr. 107).

In seinen Briefen an Heyde bestellte Gottsched gelegentlich Grüße an dessen Kollegen, den Konrektor am Geraer Rutheneum Johann Gottfried Hauptmann. Dadurch ermutigt, eröffnete Hauptmann den Briefwechsel. Er klagte über die jahrelange Verzögerung seiner Lykurgausgabe, in der die „Dankschuld“ gegen seine Leipziger Lehrer (Nr. 199), unter ihnen Gottsched, in einer Widmung zum Ausdruck gebracht werden sollte. Er stellte eine Reihe deutschsprachiger Veröffentlichungen in Aussicht und bat um die Begutachtung beigegebener Gedichte.

Auf Heydes Ermutigung zu einem Brief berief sich auch Gottfried Leyser und bat um die gerechte Beurteilung seiner eigenwilligen Veröffentlichung: Der dem weiblichen Geschlecht gewidmete und aus diesem Grund auch an die Gottschedin versandte Text zeichnet sich durch den Verzicht auf den Buchstaben $r$ aus. Daß er für diesen, in zwei Rezensionen zuvor mißbilligten, Text ausgerechnet im Hause Gottsched Verständnis suchte, spricht nicht für die Kenntnis der diese Art von Spielformen ablehnenden Gottschedschen Poetologie.

Seit fast einem Jahrzehnt ruhte die Korrespondenz mit Rahel Sophie von Marschall, der Gottsched einst den zweiten Band der Vernünftigen Tadlerinnen gewidmet hatte. Sie genoß, ohne tatsächlich etwas veröffentlicht zu haben, einen Ruf als Übersetzerin. ${ }^{28}$ In ihrem Brief an L. A. V. Gottsched reagierte sie auf die Zusendung der jüngsten Gedichte des Ehepaares Gottsched mit Ausdrücken der Wertschätzung, die noch übertroffen werden von enthusiastischen Formulierungen ihres Sohnes Heinrich Wilhelm, der

${ }^{28}$ Vgl. Gottlieb Siegmund Corvinus: Nutzbares, galantes und curiöses Frauenzimmer=Lexicon. Frankfurt am Main; Leipzig: Johann Friedrich Gleditschs Sohn, 1739, Sp. $1021 \mathrm{f}$. 
bei ihr, zurückgezogen von der Welt, in Crossen wohnte. Über weitere persönliche oder Briefkontakte ist nichts bekannt.

Wie zugesagt, hatte Gottsched bei Johann Friedrich Wilhelm Jerusalem dafür geworben, Johann Daniel Overbeck eine Helmstedter Professur anzuvertrauen. Jerusalem hatte den Vorschlag weitergeleitet, gab aber durch den Verweis auf prominente Bewerber zu verstehen, daß er Overbeck keine Chancen einräumte. Auch in den Briefen dieses Bandes lud Jerusalem Gottsched nach Braunschweig ein. Für die mit Jerusalems Schwager Pfeiffer geplante Reise wurden schon Termine ins Auge gefaßt. Es blieb bei der Planung, die Reise kam nicht zustande.

Vom Briefwechsel der Gebrüder Gottsched aus den vierziger Jahren ist kaum etwas überliefert. Daß Gottsched seinen Kasseler Bruder Johann Heinrich - wie sicherlich auch die Königsberger Angehörigen - von den Ereignissen seiner Reise detailliert unterrichtet hat, ist Johann Friedrich Reiffsteins Mitteilung zu entnehmen: „Die ausführliche Reisebeschreibung ist in der Gemeine Dero hiesigen Ihrigen zu wiederholten mahlen gelesen worden“ (Nr. 38). Nach unserem Kenntnisstand dürfte zu dieser Lesegemeinde neben der Familie des Bruders und Reiffstein Friedrich Groschuff gehört haben. Reiffstein setzte Gottsched über Vorfälle und Ergehen der Kasseler Gottschedfreunde in Kenntnis, rühmte Gottscheds jüngste Dichtungen, unterrichtete über seine Malereien und tat sich noch immer schwer, ein geeignetes Thema aus der preußischen Geschichte für ein größeres dichterisches Werk zu finden, das Gottsched von ihm erwartete. Unter dem Gesichtspunkt von Loyalitäten und Identitätsbestimmungen in der Mitte des Aufklärungsjahrhunderts ist es aufschlußreich, daß Gottsched seine Erwartung mit einem Appell an Reiffsteins preußischen Patriotismus verknüpfte. Reiffstein wollte nicht widersprechen, wies aber angesichts des wohlwollenden Empfangs durch sein „gegenwärtiges neues Vaterland“ auf den Loyalitätskonflikt hin, der sich ergäbe, wenn er sich „zu der Zeit als einen eifrigen Preußen zeigen solte, in welcher ich schon ein guter Heße hätte seÿn müßen“ (Nr. 206). Schon seit längerem hatte Reiffstein im Auftrag und für die Bibliothek des hessischen Hofmarschalls Heinrich Wilhelm Julius von Lindau Veröffentlichungen des Ehepaares Gottsched nach Kassel geordert. Rang und literarische Interessen empfahlen den Hofmarschall für die Aufnahme in die Königsberger Deutsche Gesellschaft, die von Reiffstein angeregt, von Gottsched befürwortet und von Flottwell vollzogen wurde. Lindau dankte Gottsched in einem emphatischen Schreiben für die Vermittlung und sicherte seine bleibende Neigung zur Gelehrsamkeit und zur deutschen Sprache zu. 
Zur Michaelismesse war der zweite Teil von Friedrich Groschuffs Horazübersetzung erschienen. Die Übersetzung zielte darauf ab, den sachlichen Gehalt der Dichtung speziell für jüngere Leser zu erschließen. Eine angemessene Wiedergabe der poetischen Qualitäten des lateinischen Textes hielt Groschuff für aussichtslos. Nach der Veröffentlichung wurde er von Zweifeln am Sinn seines Unternehmens geplagt, sicherlich auch wegen des miserablen Verkaufs; „der gantz und gar sich nicht äußernde Abgang schreket ihn und den Verleger am meisten“, schrieb Reiffstein (Nr. 38). Die bereits gedruckte Widmung an den Landesherrn, Statthalter Wilhelm VIII., wurde auf Anraten des Kammerpräsidenten Friedrich Wilhelm von Borck, Groschuffs Dienstherrn, unterdrückt. Auch die stattdessen vorgenommene äußerst knappe Widmung an die Königsberger Deutsche Gesellschaft kam erst nach dem Vertrieb des ersten Bandes zustande. Sie fehlt infolgedessen in den Exemplaren, die unserer Auskunft zugrundelagen, das Buch sei ohne Widmung erschienen (Band 12, Nr. 123, Erl. 11 u. ö.). Groschuff besorgte die Veröffentlichung jüngster Gedichte Gottscheds in Kassel und regte eine Neuausgabe der plattdeutschen Gedichte Johann Laurembergs an.

Christian Gottlieb Spener gehörte lange Zeit als dessen Sekretär dem Hause Ernst Christoph von Manteuffels an und war daher ein guter Bekannter Gottscheds. Nach Manteuffels Tod trat Spener in den Dienst des Hauses Brandenburg-Ansbach. Sein Brief aus Ansbach, der letzte, der von ihm überliefert ist, ist ein Zeugnis für Gottscheds Bemühung um die Hartmannsche Münzsammlung.

Auf der Reise nach Wien hatte das Ehepaar Gottsched mehrere Tage bei Maria Regina Thomasius in Nürnberg Station gemacht, die Gastgeberin wurde zur Herzensfreundin der Gottschedin. Mit einer knappen Danksagung für ein Buchgeschenk endet der überlieferte Briefwechsel. Aus anderer Quelle ist zu erfahren, daß der Briefwechsel mit Leipzig lebenslang angedauert hat, nur dürfte die Korrespondenz auch hier von Frau Gottsched geführt worden und mit ihrer Sammlung verlorengegangen sein (Band 14, S. LII).

Ernst Friedrich Justin Heimreich von Heimenthal gehörte zum Bekanntenkreis der Frau Thomasius. Von der Begegnung mit dem in schwedischen und hessischen Diensten stehenden Diplomaten berichtete Gottsched in seiner veröffentlichten Reisebeschreibung. Heimenthal seinerseits versicherte im ersten Brief, er lasse Gottsched Gerechtigkeit widerfahren und arbeite gegen „Ubelwollender Leüte Conatus“ (Nr. 59). Offenbar war 
Gottsched in Heimenthals Gesellschaftskreisen umstrittenes Gesprächsthema. Er trug Gottsched verschiedene Anliegen vor, die von der Klärung des weiteren Bezugs des von ihm einst subskribierten Zedlerschen Lexikons, der Erkundigung nach der Verfügbarkeit Tschirnhausscher Brennspiegel, Gottscheds Bereitschaft, einen adligen angehenden Studenten in seine Obhut zu nehmen, bis zur Einschätzung des Dekans der Juristenfakultät, den Heimenthal für ein Gutachten konsultieren will, reichen. Selbst die beiden Briefe an Luise Adelgunde Victorie Gottsched enthalten einen Auftrag. Frau Gottsched sollte erkunden, ob die in Leipzig lebende verwitwete Herzogin von Kurland eine adlige Person aus Heimenthals Bekanntschaft zeitweise in ihr Haus aufnehmen würde.

Auch die Bibliothek des Nürnberger Patriziers Hieronymus Wilhelm Ebner von Eschenbach wurde in Gottscheds Reisebericht erwähnt. Gottsched sandte ihm folglich ein Exemplar des Drucks. Mit der Danksagung und dem Angebot, die Bibliotheksbestände zu nutzen, wurde dessen derzeitiger Hofmeister Christoph Melchior Schmidbauer beauftragt. Da keine weiteren Briefe vorliegen, scheint Gottsched davon keinen Gebrauch gemacht zu haben.

Während des Aufenthalts in Nürnberg dürfte Gottsched auch den Journalisten Johann Gottfried Gross kennengelernt haben. Dessen Zeitung Auszug der neuesten Weltgeschichte ist mediengeschichtlich von Bedeutung, weil hier erstmals neben der üblichen nüchternen Information auf Unterhaltung Wert gelegt wurde und der Journalist Gross das Recht in Anspruch nahm, Ereignisse mit kritischen Kommentaren zu begleiten. ${ }^{29}$ Die Zeitschrift erreichte ein großes Publikum, und so hat Gottsched es gewiß geschätzt, daß sein an Gross verschickter Reisebericht an die Öffentlichkeit gelangte und Gerüchten über seinen Verbleib in Wien entgegenwirken konnte. Gross' Bitten um Besorgung von Breitkopfschen Lettern und um Vermittlung eines Mitarbeiters für seine Zeitschrift hat Gottsched umgehend befolgt, wenn auch das gewünschte Resultat vorerst nicht zustandekam.

Auf Gottscheds Reise nach Wien war die Station Regensburg mit einem Besuch der Bibliothek des Superintendenten Johann Matthäus Barth verbunden. Wie verabredet, sandte Barth ein Manuskript, das Gottsched „in Leipzig unterzubringen" zugesagt hatte (Nr. 212), und überließ ihm eine Chronik für die Sammlung älterer deutscher Literatur.

${ }^{29}$ Vgl. Jürgen Wilke: Grundzüge der Medien- und Kommunikationsgeschichte. Köln u. a. 2008 , S. $88 \mathrm{f}$. 
Wie Gottsched hat Jacob Brucker, der Augsburger Pfarrer und Freund, seine umfängliche Korrespondenz sorgsam gesammelt. Die vorgesehene Übergabe an die Bibliothek des Augsburger Anna-Kollegiums, ${ }^{30}$ die den Bestand an Gottschedbriefen um weit mehr als hundert Stück vermehrt hätte, ist aus unbekannten Gründen unterblieben. Die Suche nach Briefen förderte nur die fragmentarische Abschrift eines einzigen Schreibens zutage, die im vorliegenden Band mitgeteilt wird: Auf eine Frage Bruckers hin gab Gottsched ein Urteil über einen in Leipzig studierenden Augsburger Studenten ab und eröffnete Perspektiven für dessen weiteren Verbleib. Diese Aussagen zur Person gelangten an die amtlichen Unterstützer, wurden wohl ad acta genommen und haben auf diese Weise die Zeiten überdauert. Entgegen seiner Planung konnte Brucker das seinerseits fertiggestellte 8. Zehend des Bilder=sals nicht übersenden. Durch eine langwierige Krankheit Johann Jacob Haids war die Fertigstellung in Verzug geraten. Erstmals verzichtete Brucker auf die Aufnahme eines Wissenschaftsmäzens. In den früheren Bänden war diese Position durch große Namen besetzt. Es sei schwer, geeignete Personen zu gewinnen, meinte Brucker jetzt. Die sich selbst ins Spiel brachten, erfüllten Bruckers Kriterien nicht. Namen nannte er gegenüber Gottsched nicht, aber aus dieser wiederholt angebrachten Äußerung wird deutlich, daß Brucker seine Maßstäbe wahrte, vornehme Namen nicht als Schmuckelemente suchte, sondern die Aufnahme als Mäzen in einem präzisen Sinn als Würdigung eines Einsatzes für die Wissenschaften verstanden wissen wollte. Für den zweiten Band seines Ehrentempels brachte Brucker eine beträchtliche Anzahl von Geistesgrößen des 16. und 17. Jahrhunderts in Vorschlag. Als Gottsched die Konzentration auf Philologen beanstandete, versicherte Brucker, auch Mathematiker und Philosophen einbeziehen zu wollen. Da aber die Kauflust in keinem Verhältnis zum allgemeinen Beifall für den Ehrentempel stand, war der Verleger Haid für einen weiteren Band nicht zu gewinnen. Brucker bestätigte einmal mehr die Popularität von Gottscheds Neuem Büchersaal, „die glückliche und scharfsinnige Wahl und Abwechslung der Materien hat dieses Tagebuch in unserer Stadt auch KaufLeuten und andern, nicht eben vom Studieren Profeßion machenden Personen sehr angenehm und geläufig gemacht“. Einen Bildungsschub scheint die Lektüre des Büchersaals jedoch

30 Vgl. Franz Anton Veith: Bibliotheca Augustana Complectens Notitias Varias De Vita Et Scriptis Eruditorum, Quos Augusta Vindelica Orbi Litteratae Vel Dedit Vel Aluit. Band 8. Augsburg 1792, S. 2-55, 22. 
nicht bewirkt zu haben, denn im selben Brief schreibt Brucker, daß „in einer so großen Stadt, als Augspurg ist ehender 100. anzutreffen, mit denen ich von Wechselbriefen reden kan, als 2. oder 3. die zu einer die schönen Wissenschafften betreffenden Unterredung Lust, oder auch Geschicke haben" (Nr. 146). Wie so oft schickte Brucker seine neuesten Kalender und andere Veröffentlichungen, beispielsweise über den frühen Augsburger Buchdruck. Er stellte wissenschaftliche Projekte vor, teilte Gelehrtennachrichten mit und unterrichtete Gottsched detailliert über die Auswahlkriterien bei der Wahl eines Studienortes für seinen achtzehnjährigen Sohn.

„Der unsterbliche Ruhm einer Gottschedischen Wißenschaft hat nun auch den düstern Schwartzwald durchdrungen“, begann Joseph Anton von Bandel aus Konstanz seinen Brief an Gottsched, in dem er den „elenden Stand" beklagte, in den „die Wißenschaften und Teütsche Sprache beÿ uns Catholicken verfallen" (Nr. 185). Bandel erwarb sich später einen Namen als zum Grobianismus neigender antiprotestantischer und antiaufklärerischer Polemiker. Was er unter dem ,ausgesuchten Catalogo pour les belles lettres" verstand, um den er Gottsched bat, ist nicht genau zu bestimmen. Da sich Bandel schon in diesem ersten und einzigen Brief als Kontrahent des Zeitungsschreibers Johann Gottfried Gross vorstellte, mit dem Gottsched erst kürzlich eine freundschaftliche und für seine mediale Präsenz hilfreiche Verbindung aufgenommen hatte, ist es wenig wahrscheinlich, daß er sich auf Bandels Annäherung eingelassen hat.

Die vergleichsweise große Anzahl an Briefen aus Wien und dortigen Korrespondenten ist eines der auffälligsten Merkmale dieses Bandes. Etliche Absender nahmen noch Bezug auf Gottscheds Aufenthalt oder warteten mit einer Danksagung auf, ohne daß eine Korrespondenz in Gang kam. Friedrich Wilhelm von Haugwitz bedauerte, daß Gottsched ihn nicht aufgesucht habe und stellte Überlegungen über ein Studium seines Sohnes in Leipzig an. Joseph Wenzel von Liechtenstein bedankte sich für die Zusendung des von ihm erbetenen Buches. Im Band sind auch die beiden in Wien lebenden, in der Literatur oft verwechselten Verwandten namens Marci mit je einem Schreiben vertreten. Der ältere Jean Marci, lebenslang als Hofmeister mit der Harrachschen Familie verbunden, sagte einen finanziellen Beitrag für die geplante Denkschrift auf Friedrich August von Harrach zu (Nr. 46). Sein Neffe, der Hofmathematiker Jean François Marci, unterrichtete über den Stand des offenbar in Absprache mit Gottsched getroffenen Plans einer kaiserlichen Druckerei. Carl Maximilian von Dietrichstein dankte für Gottscheds Glückwunsch zur Aufnahme in den 
Orden vom Goldenen Vlies (Nr. 49). Maria Carolina von Trautson berichtete über Empfindungen und Reaktionen, die Gottscheds Dichtungen bei ihr selbst und bei der Kaiserin hervorgerufen haben. Über Carl Joseph von Batthyan, den Erzieher des Erzherzogs und späteren Kaisers Joseph, erwarb Gottsched die Genehmigung, die neue Auflage seiner Redekunst dem kaiserlichen Sproß zum 9. Geburtstag zu widmen.

Johann Friedrich Barisién meldete sich aus Wien, nachdem er ein Jahr zuvor Gottsched aus seinem Heimatort Saalfeld um eine Stellenvermittlung gebeten hatte. Gottsched hatte ihn an den Zeitungsschreiber Johann Gottfried Gross empfohlen. Das Engagement stand unmittelbar bevor, als Barisién ein anderes Dienstverhältnis einging. Erst dreieinhalb Jahre später wandte er sich erneut an Gottsched. Wie Barisién gehörte Joseph Heinrich Engelschall zu Gottscheds Schülern. Auch ihm konnte Gottsched ein Stellenangebot unterbreiten, aber Engelschall hatte mittlerweile in Wien Fuß gefaßt. Nach Hofmeistertätigkeit und Privatvorlesungen gelangte er auf Professuren in verschiedenen Wiener Bildungsstätten, um schließlich nobilitiert und zum k. k. Wirklichen Geheimen Rat ernannt zu werden. Mehr als die zwei Briefe des vorliegenden Bandes sind nicht überliefert. Friedrich Wilhelm Weiskern, der Schauspieldichter und Theaterdirektor, konnte dank seiner Kontakte in vornehme Kreise Gottscheds Dichtungen an die gewünschten Adressen übergeben und Gottsched über die Resonanz informieren.

Johann Christoph Löschenkohl hatte in Leipzig studiert, war Mitglied der von Gottsched geleiteten Vormittägigen Rednergesellschaft und hatte als Herausgeber ihrer Reden eine Schlüsselstellung eingenommen. Als Privatsekretär des kaiserlichen Kammerherrn und Diplomaten Nicolaus Graf Esterhasy konnte er sich schon gelegentlich für Gottsched verwenden. Auch in Wien erwies sich die Verbindung als hilfreich. Das Arrangement der Audienz verdankte sich Esterhasy und seiner Verbindung zur Fürstin Trautson (vgl. Band 14, S. 609, Z. 10-17; Band 15, Nr. 1). Die kaiserlichen Geschenke gelangten über die Fürstin Trautson an Esterhasy, der für die weitere Besorgung zuständig war. Man kann davon ausgehen, daß sein Privatsekretär Löschenkohl, in dessen Handschrift auch Esterhasys Briefe an Gottsched geschrieben sind, eine gewichtige Rolle in den Unternehmungen zugunsten des Leipziger Professors gespielt hat. Gottsched hatte ihm seine geheimen Wünsche über eine Zukunft in Wien anvertraut. Allerdings lassen seine Briefe mit ihren dezidierten Regieanweisungen nach Leipzig und der Forderung, nichts ohne vorherige Absprache und 
nichts an Esterhasy vorbei zu unternehmen, ein hohes Bewußtsein der eigenen Bedeutung und einen klaren Alleinvertretungsanspruch erkennen. Der in Löschenkohls Briefen vermittelte Eindruck unermüdlichen und gut kalkulierten Einsatzes zugunsten Gottscheds wird indes durch drastische Bemerkungen Franz Christoph von Scheybs über die Insuffizienz des Duos Esterhasy/Löschenkohl konterkariert. Gottsched war in einer mißlichen Lage. Einerseits sah er sich mit Löschenkohls Forderung konfrontiert, „sich nicht an mehrere Leute allhier zu addressiren, denn viele Köche versaltzen die Suppen“, was mit deutlichem Bezug auf Scheyb geschrieben war (Nr. 53). Andererseits lästerte Scheyb über Löschenkohls Fahrigkeit und Trägheit. Einerseits war die Audienz durch Esterhasy und dank seiner Verbindung zur Fürstin Trautson zustandegekommen. Andererseits konnte Scheyb durch eine dichte Abfolge von Briefen und die anschauliche Beschreibung seiner Aktivitäten Gottsched von seinem Eifer überzeugen. Gottsched umging eine Entscheidung. Als im März 1750 Esterhasy beabsichtigte, den zweiten Band der Geschichte der königlichen Akademie der schönen Wissenschaften zu Paris mit dem vorangedruckten Danksagungsschreiben der Übersetzerin L. A. V. Gottsched über die Fürstin Trautson an die Kaiserin gelangen zu lassen, mußte er zur Kenntnis nehmen, daß ihm Scheyb zuvorgekommen war. Aus dem exklusiven Förderer zu einem sekundären Unterstützer zu werden, entsprach nicht dem Selbstverständnis des Grafen und seines Sekretärs Löschenkohl. Dessen Brief, in dem dieser Vorgang zur Sprache gebracht wurde, schließt mit der Bemerkung, „da übrigens der H. v. Scheib vermuthlich von denen hiesigen Umständen alles an Ew: HochEdelgeb: weitläuftig berichten wird, so bleibet mir nichts mehr übrig als mich zu Dero und der Frau Gemahlin ... gütigsten Andencken und gewogenheit zu recommandiren“. Die Korrespondenz war damit beendet.

Scheybs Briefe übertreffen sowohl in der Anzahl als auch an Umfang alle anderen Schreiben des Bandes. Sie sind mitunter sehr anschaulich und konkret. So schilderte er die Suche nach einer Gottschedschen Büchersendung im Wiener Behördendickicht oder gab einen Dialog mit der Fürstin Trautson wörtlich wieder. Auch andere Unternehmungen, zumal solche im Auftrag oder zugunsten Gottscheds, wurden genauestens beschrieben. Das Charakteristische der Briefe ist allerdings eher die stilistische Aufschäumung. Einschübe aus dialektalen, englischen, italienischen, französischen, lateinischen, spanischen und nicht selten verballhornten Wendungen finden sich in allen Briefen. Burleske Selbstkommentare, Interjektionen und 
vulgärsprachliche Wörter wie Fänckerl, Teixel gehören zum Standardrepertoire, auch Kalauer wie Kohlenlösch für Löschenkohl kommen vor. Mitunter galoppiert Scheybs Sprachphantasie davon, so daß Leser und Kommentatorin Mühe haben, seinen Ausführungen einen Sinn abzugewinnen. Mit dem hübschen Satz „Ich muß schliessen, denn wenn ich nicht aufhöre, so werde ich nie förtig, sagt unser kürchenlehrer H. W." beruft sich Scheyb gelegentlich auf den Darsteller bzw. die Figur des Hanswurst, die Gottsched bekanntlich als Erscheinung des Theaters mit Nachdruck bekämpft hat. Diese Referenz ist symptomatisch. Tatsächlich tritt einem die Scheybsche Briefkunst eher als Hanswurstiade denn als nüchtern-klare Komposition im Sinne Gottscheds entgegen. Nach eigenem Bekenntnis und Selbstverständnis galt Scheyb in Wien jedoch als "ausgeschrÿener Gottschedianer“ (Nr. 138). Da Scheyb in der Gottschedschen Briefsammlung bis ans Ende und mit weit über hundert Briefen vertreten ist, die allesamt auch beantwortet wurden, muß Gottsched an dem ungestümen Wiener Korrespondenten und einem Stil Gefallen gefunden haben, der sich bezeichnenderweise erst nach der persönlichen Begegnung mit den Gottscheds ungebremst artikulierte. Das Fehlen der Antwortbriefe Gottscheds ist hier noch bedauerlicher als anderswo, hätte man doch gern gewußt, wie sich der Leipziger Regelpoetiker auf diesen turbulenten Brieffreund eingestellt hat. Als thematische Schwerpunkte seiner Briefe können die Überlegungen zu Gottscheds Wirken in Wien, die Erörterungen über die Ausgabe der Gedenkschrift auf Scheybs ehemaligen Dienstherrn Friedrich August von Harrach oder die gegen das jesuitische Schulwesen gerichtete französische Schrift gelten, von der erst durch Kombination der mehr oder weniger verschleierten Bemerkungen und durch den Hinweis eines Außenstehenden (Nr. 44) erkennbar wird, daß der von Scheyb als Bickolo bezeichnete Verfasser er selbst war. Die von Frau Gottsched übersetzte Version wurde im Neuen Büchersaal unter dem Titel „Abhandlung, von der Unnützlichkeit der scholastischen Art, zu studieren, so wie sie in den Schulen der Katholischen in Deutschland getrieben wird" veröffentlicht (vgl. Nr. 69, Erl. 11). Scheyb stellte die Übersetzung weit über sein französisches Original, wie er auch ihre verbessernden Eingriffe in seine „Harrachiade“ nicht genug zu rühmen wußte.

Aus der Schweiz erhielt Gottsched Post vom Pfarrer Johann Conrad Fueßlin, der sich der Polemik gegen Johann Jacob Breitinger verschrieben hatte und Gottscheds Unterstützung für die Veröffentlichung einer gegen Breitinger gerichteten Satire erbat. 
Gottscheds Reisebericht wurde von Angelo Maria Querini umgehend beantwortet. Der Kardinal bot weiterhin seine Dienste an. Daß der Briefwechsel gleichwohl mit diesem Schreiben endet, ist verwunderlich, denn die exakte Beschreibung deutscher Handschriften der Vatikana, die Gottsched erbeten und ihr Bibliothekar Querini zugesagt hatte, lag noch nicht vor. ${ }^{31}$ Auch die versprochene Überarbeitung der an Querini gesandten italienischen Übersetzung des Sterbenden Cato $^{32}$ stand noch aus. Sollte Gottsched die Verbindung abgebrochen haben, weil sie Gerüchten Nahrung gab?33 Oder hat er sich zurückgehalten, weil nach Jacob Bruckers schroffen Urteilen und Formeys öffentlichem Schlagabtausch nun auch sein katholi-

${ }^{31}$ Gottsched hatte von Querini wunschgemäß ein Verzeichnis deutschsprachiger Handschriften in der Vatikanbibliothek erhalten und trug daraufhin die Bitte um präzisere Beschreibung vor; vgl. unsere Ausgabe, Band 14, Nr. 22 und 29. Querinis entsprechende Zusage (Band 14, Nr. 60) wurde nicht eingelöst. Unter der im Auktionskatalog der Gottschedin aufgeführten „Anzeige einiger Handschriften der Vaticanisch=Pfälzischen Bibliothek“ dürfte das genannte Verzeichnis zu verstehen sein; vgl. Appendix ad Catalogum Bibliothecae quam L. A. V. Gottschedia ... collegit. In: Catalogus Selectae Bibliothecae Quam L. A. V. Gottschedia Ex Gente Kulmia Peculiari Opera Collegit, Cuius Ut Et Appendicis Auctio Lipsiae D. XVI. Novembr. MDCCLXVII. In Aedibus Breitkopfianis Vulgo Der Goldne Baer Dictis Habebitur. Lipsiae, Litteris Breitkopfianis. S. 4, Nr. 24.

32 Der in unserer Ausgabe, Band 14, S. 364 namentlich unbekannte Translator dürfte durch die folgenden Informationen identifiziert sein: Christian Felix Weiße schrieb am 5. Januar 1776 an Heinrich Wilhelm von Gerstenberg, eine Übersetzung sei imstande, ,auch wohl einem ganz schlechten Originale einen Werth zu geben. Ich habe dies an dem von Moltern ins Italiänische übersetzten Cato von Gottscheden gesehen“. Gabriele von Koenig-Warthausen: Elf Briefe aus dem Kreise Gerstenbergs. In: Archiv für das Studium der neueren Sprachen 89 (1935), S. 10-17, 185-194, 13. Aller Wahrscheinlichkeit nach ist hier Friedrich Valentin Molter (1722-1808) gemeint, der um 1750 Übersetzungen aus dem Italienischen und eine toskanische Sprachlehre verfasst hat (vgl. Killy 8, S. 299 f.). Seine Verse an Gottsched (vgl. unsere Ausgabe, Band 10, S. LV) belegen die Bekanntschaft mit Gottsched. Über die Übersetzung, die Weiße, um 1749 zum Schülerkreis Gottscheds gehörig, gelesen hat, konnte nichts ermittelt werden.

33 In einem Brief des Satirikers Gottlieb Wilhelm Rabener findet sich die Bemerkung über Gottsched: „Vielleicht wandert er mit aufs heilige Jahr nach Rom, um dem Cardinal Quirini zu sagen, daß er sein groser Gönner sey. Der Cardinal hat in Sachßen seinen Credit ziemlich verlohren, und Formey hat ihm vollends den lezten Druck gegeben." Rabener an Johann Jakob Bodmer, Leipzig 9. September 1749. In: Gottlieb Wilhelm Rabener: Briefwechsel und Gespräche. Hrsg. von E. Theodor Voss unter Mitarbeit von Jan Müller. Göttingen 2012, S. 129-132, $131 \mathrm{f}$. 
scher Freund Scheyb ihn vom schlechten Leumund des Kardinals informierte? 1755 beklagte Gottsched nach Querinis Tod in einem Kondolenzbrief an Antonio Sambuca den Verlust eines großen Gönners und Freundes. ${ }^{34}$

Aus Kopenhagen bzw. Blågård, seinem Garten bei Kopenhagen, wie er die fürstliche Sommerresidenz bescheiden nannte, meldete sich der Kammerherr a. D. Carl Adolph von Plessen, um dem ungeduldigen Gottsched wiederholt zu versichern, daß die dem dänischen König gewidmete Ausgabe seiner Reden bei Hofe huldreich aufgenommen wurde. Ob die angekündigte Gegengabe Gottsched erreicht hat, war nicht festzustellen. Plessens Briefe enden mit diesem Band, ohne eine Auskunft darüber zu enthalten.

Rüdiger Otto

${ }^{34}$ Leipzig, UB, ASL 3022. 
